\title{
Pim-1 Protects Retinal Ganglion Cells by Enhancing Their Regenerative Ability Following Optic Nerve Crush
}

\author{
Shoumei Zhang ${ }^{1,4}$, Li Shuai ${ }^{2}$, Dong Wang ${ }^{1}$, Tingting Huang ${ }^{1}$, Shengsheng Yang ${ }^{3}$, \\ Mingyong Miao ${ }^{3}$, Fang Liu ${ }^{1}$ and Jiajun $\mathrm{Xu}^{1 *}$ \\ ${ }^{1}$ Department of Anatomy, Second Military Medical University, Shanghai 200433, ${ }^{2}$ Department of Health Administration, \\ Second Military Medical University, Shanghai 200433, ${ }^{3}$ Department of Biochemistry and Molecular Biology, Second Military \\ Medical University, Shanghai 200433, ${ }^{4}$ Translational Medical Center for Stem Cell Therapy, Shanghai East Hospital, Tongji \\ University School of Medicine, Shanghai 200120, China
}

Provirus integration site Moloney murine leukemia virus (Pim-1) is a proto-oncogene reported to be associated with cell proliferation, differentiation and survival. This study was to explore the neuroprotective role of Pim-1 in a rat model subjected to optic nerve crush (ONC), and discuss its related molecules in improving the intrinsic regeneration ability of retinal ganglion cells (RGCs). Immunofluorescence staining showed that AAV2Pim-1 infected 71\% RGCs and some amacrine cells in the retina. Real-time PCR and Western blotting showed that retina infection with AAV2Pim-1 up-regulated the Pim-1 mRNA and protein expressions compared with AAV2-GFP group. Hematoxylin-Eosin (HE) staining, $\gamma$-synuclein immunohistochemistry, Cholera toxin B (CTB) tracing and TUNEL showed that RGCs transduction with AAV2-Pim-1 prior to ONC promoted the survival of damaged RGCs and decreased cell apoptosis. RITC anterograde labeling showed that Pim-1 overexpression increased axon regeneration and promoted the recovery of visual function by pupillary light reflex and flash visual evoked potential. Western blotting showed that Pim1 overexpression up-regulated the expression of Stat3, p-Stat3, Akt1, p-Akt1, Akt2 and p-Akt2, as well as $\beta$ III-tubulin, GAP-43 and 4E-BP1, and downregulated the expression of SOCS1 and SOCS3, Cleaved caspase 3, Bad and Bax. These results demonstrate that Pim-1 exerted a neuroprotective effect by promoting nerve regeneration and functional recovery of RGCs. In addition, it enhanced the intrinsic regeneration capacity of RGCs after ONC by activating Stat3, Akt1 and Akt2 pathways, and inhibiting the mitochondrial apoptosis pathways. These findings suggest that Pim-1 may prove to be a potential therapeutic target for the clinical treatment of optic nerve injury.

Key words: Pim-1, Nerve regeneration, Retinal ganglion cell, Optic nerve injury

\section{INTRODUCTION}

Injury of the central nervous system (CNS) and optic nerve may damage neurons, resulting in regenerative failure $[1,2]$. The main causes include massive retinal ganglion cell (RGC) death $[3,4]$, the decreased ability of RGC regeneration $[5,6]$. Equally, the extrinsic factors inhibiting nerve growth include lack of cells to guide axo-

Submitted March 26, 2020, Revised June 22, 2020,

Accepted June 22, 2020

* To whom correspondence should be addressed. TEL: 86-21-81870950, FAX: 86-21-81870955 e-mail:xujiajunsmmu@163.com nal regeneration[7], neurotrophic factor deficiency [8], inhibition of the regeneration microenvironment, myelin debris, glial scarring $[9,10]$, neuroinflammation, and lack of facilitatory molecules $[11,12]$. The decreased intrinsic regenerative ability of RGCs after optic nerve crush (ONC) is generally accepted as the key factor for the failure of optic nerve regeneration after injury.

About two weeks after optic nerve injury, the number of RGCs decrease sharply to $40 \sim 50 \%$ of the normal number, rendering it difficult to regenerate the optic nerve effectively [3,4]. Recent research has focused on improving the intrinsic regenerative capacity of RGCs. Some studies activated the latent regeneration of RGCs by intraocular injection of crystallin protein, expecting that
Copyright @ Experimental Neurobiology 2020. www.enjournal.org
This is an Open Access article distributed under the terms of the Creative Commons Attribution Non-Commercial License (http://creativecommons.org/licenses/by-nc/4.0) which permits unrestricted non-commercial use, distribution, and reproduction in any medium, provided the original work is properly cited. 
axonal regeneration could reach the distal nerve through the optic nerve crush site, but they achieved a limited number of regenerative axons. B-Raf activation of the RAF-MEK pathway, especially in combination with knockout of tension homology deleted on chromosome ten (PTEN), could effectively promote the regeneration of the optic nerve after injury in a rat model [5]. Vitreous injection of PTEN-shRNA, adeno-associated virus 2 (AAV2)-ciliary neurotrophic factor (CNTF) and cAMP analogues could promote the regenerative axons into the mouse suprachiasmatic and suprachiasmatic nuclei to form synapses $[13,14]$. Similarly, experiments with AAV2-brain-derived neurotrophic factor (BDNF), AAV2CNTF and growth-associated protein 43 (GAP-43) demonstrated that AAV2-CNTF played the most important role in promoting RGC survival and axonal regeneration [15]. Vitreous injection of AAV2-DCX-like kinase (DCLKs) promoted axon regeneration in a PTEN knockout mouse model, where axons could reach the optic chiasma [16]. RGC transduction with AAV2-Neuritin 1 (Nrn1) promoted retinal ganglion cell survival and axonal regeneration following ONC in a mouse model [17]. These results suggest that targeting the appropriate gene could enhance the intrinsic regenerative ability of RGCs and promote regeneration of the damaged optic nerve.

Pim-1 is a common downstream effector molecule of many cytokines, growth factors such as IL-2, GCSF and HGF, and more importantly four signaling pathways (JAK-STAT, AKT, MAPK and NF-kB). It can promote cell proliferation, differentiation and survival by phosphorylating the downstream substrates $[18,19]$. Pim1 is not only highly expressed in hematopoietic tissues including the thymus, spleen and bone marrow but distributed in nonhematopoietic tissues such as the oral epithelium, prostate, visual cortex, hippocampus, striatum and retina [20]. It can inhibit tumor cell apoptosis, facilitate cell proliferation[19], participate in angiogenesis and vascular smooth muscle cell proliferation and survival [21], promote cardiac progenitor cell proliferation and survival, protect damaged cardiomyocytes [22, 23], adjust neuronal excitability, plasticity and neurotransmitter release [24,25], and mediate damaged neuronal survival and apoptosis [26]. In addition, it is also involved in the protection of the respiratory epithelium [27], inflammatory and immune responses [28], and promotes bone marrow stem cell proliferation and survival [29]. Pim-1 is expressed in both embryonic mouse retina and embryonic zebrafish ganglion cell layer (GCL) to promote the neural development of the retina $[20,30]$. Pim-1 is a common downstream effector molecule of many cytokines and growth factors. Regulating a molecule in upstream may have limited effect on promoting cell proliferation, differentiation and survival. If we modulate the downstream molecule Pim-1, the effect in promoting cell proliferation, differentiation and survival may act as a sum of all the molecules in upstream. At present, most studies on Pim-1 focus on tumors, myocardial protection and blood vessels, and few studies address it roles in nerve injury and regeneration involving the retina.

For the first time, we constructed an AAV2-Pim-1 vector and infected RGCs to evaluate the treatment efficacy of common downstream effector molecule Pim-1 in a rat ONC model to see whether it could protect RGCs against apoptosis, increase cell survival, improve RGC function, and promote regeneration of injured axons.

\section{MATERIALS AND METHODS}

\section{Experimental animals and groups}

Young male Sprague-Dawley (SD) rats weighing 90 110 g (Laboratory animal center of the Second Military Medical University, Shanghai, China) were bred at a constant temperature and a $12 \mathrm{~h}: 12$ $\mathrm{h}$ light-dark cycle with free access to water and food. The experiment was carried out according to the guide for the Care and Use of Laboratory Animals as recommended by the National Institutes of Health, and approved by the Ethics Committee for Animal Experimentation of the said university.

The animals were equally randomized into four groups: (1) Sham group, where the animals received intravitreal injection of $2 \mu$ normal saline (NS) and the optic nerve was exposed without injury; (2) injury group, where the animals received intravitreal injection of $2 \mu \mathrm{lNS} ; 4$ weeks after injection the optic nerve was subjected to ONC and the eyeballs and optic nerve were removed 2 weeks after ONC; (3) AAV2-GFP group, where the animals received intravitreal injection of $2 \mu \mathrm{lAAV} 2$-GFP; 4 weeks after injection the optic nerve was subjected to ONC, eyeballs and optic nerve were drawn 2 weeks after ONC; and (4) AAV2-Pim-1 group, where the animals received intravitreal injection of $2 \mu$ AAV2-Pim-1; 4 weeks after injection the optic nerve was subjected to ONC, eyeballs and optic nerve were drawn 2 weeks after ONC. The rats with postoperative infection and disease were picked out of the experiment. A total of 154 rats were used in this study (Table 1).

\section{AAV2-Pim-1 production and administration}

The AAV2 virus packaging system consisted of pAOV-CAGMINI-eGFP, pAAV-RC and pHelper. Target gene Pim-1 was activated by promoter CAGMINI with neuro-specific expression. A pAOV-CAGMINI-eGFP-2A-Pim-1-3FLAG plasmid carrying the Pim-1(NM_017034) cDNA clone (Biostime Biotechnology Co., Shanghai, China) was used to produce AAV2-Pim-1. The positive PCR cloning was compared with that of the GenBank database; consistency of the comparison with the ID:NM_017034 indicated 
Table 1. Detection methods and animal groups

\begin{tabular}{ll}
\multicolumn{1}{c}{ Detection methods } & \multicolumn{1}{c}{ Animal groups } \\
\hline CTB tracing RGCs & Sham, Injury, AAV2-GFP, AAV2-Pim-1 \\
RITC tracing optic nerve & Sham, Injury, AAV2-GFP, AAV2-Pim-1 \\
Eosin-hematoxylin staining & Sham, Injury, AAV2-GF, AAV2-Pim-1 \\
Immunohistochemical staining & Sham, Injury, AAV2-GFP, AAV2-Pim-1 \\
Immunofluorescence staining & AAV2-Pim-1 group without ONC \\
TdT-mediated dUTP Nick-End Labeling & Sham, Injury, AAV2-GFP, AAV2-Pim-1 \\
Quantitative real time polymerase chain reaction & Sham, AAV2-GFP, AAV2-Pim-1 groups without ONC \\
& Sham, Injury, AAV2-GFP, AAV2-Pim-1 groups with ONC \\
Western blotting & Sham, AAV2-GFP, AAV2-Pim-1 groups without ONC \\
& Sham, Injury, AAV2-GF, AAV2-Pim-1 groups with ONC \\
Pupillary light reflex & Sham, Injury, AAV2-GFP, AAV2-Pim-1 \\
Flash visual evoked potentials & Sham, Injury, AAV2-GF, AAV2-Pim-1 \\
\hline
\end{tabular}

successful construction of the plasmid. Altogether 293 cells were transfected with the fluorescent protein eGFP expression plasmid through lipo2000, and the presence of green fluorescence $24 \mathrm{~h}$ after transfection indicated the successful transfection of AAV2Pim-1 vector. Finally, AAV2-Pim-1 was packaged at AAV2-Pim-1 drop of $5.7 \times 10^{12} \mathrm{vg} / \mathrm{ml}$ and AAV2-GFP drop of $3.57 \times 10^{12} \mathrm{vg} / \mathrm{ml}$, and stored at $-80^{\circ} \mathrm{C}$.

The experimental procedures were as follows: $5 \mu \mathrm{l}$ Hamilton microsyringe (Hamilton Co., Switzerland) was used to inject $2 \mu \mathrm{lNS}$, AAV2-GFP and AAV2-Pim-1 in the left eye of the rat as designed. Four weeks after injection, a rat model of left optic nerve damage was established with a temporary mini-cerebral aneurysm clip, and then the left eye and optic nerve were removed and tested 2 weeks post injury.

\section{Establishment of the ONC animal model}

After intraperitoneal (i.p.) injection of $10 \%$ chloral hydrate (0.4 $\mathrm{ml} / 100 \mathrm{~g}$ per rat), surgery was carried out on the left eye under a surgical microscope. Using the intraocular microscissors, an incision was made on the fascia of the sclera $2 \mathrm{~mm}$ lateral to the cornea, and the optic nerve was dissected bluntly. ONC at $2 \mathrm{~mm}$ posterior to the eyeball was induced with a temporary Yasargil aneurysm clip (Aesculap Company, Germany) for 5 s [31].

\section{Intravitreal injection}

After successful induction of abdominal anesthesia, tropicamide eyedrops were used to enlarge the rat pupils. Then, $5 \mu$ Hamliton microsyringe was slanted down into the needle on the fascia of the sclera $1 \mathrm{~mm}$ lateral to the cornea. The injection needle, which was visible through the center of the pupil, was inserted into the vitrous body slowly and was let to stay there for $3 \mathrm{~min}$. After the injection, the needle was withdrawn slowly, and finally the left eye of the rat was prevented from being infected with aureomycin ointment. It was necessary to avoid injuring the retina and lens during the whole process.

\section{CTB tracing RGCs and retinal flat mounts}

After injection of $2 \mu \mathrm{l}$ CTB (C1655-.5MG, Sigma Company, USA) into the vitreous body in all four groups, the rats were perfused with $4 \%$ paraformaldehyde (PFA)-PBS (pH 7.4) (Sinopharm, China). The eyeballs of the rats surviving 2 days after injection were removed and fixed in 4\% PFA-PBS for $4 \mathrm{~h}$. A small incision was made on the sclera $1 \mathrm{~mm}$ away from the edge of the cornea; the cornea was removed and the vitreous body was taken out under the dissecting microscope; four lines were cut diagonally on the eye cup by which the retina was spread like petals. The wrinkles were smoothened and excessive liquid was absorbed under the microscope. The slides were sealed and placed under a fluorescence microscope to observe and photograph. In each quadrant, three fields of view $(20 \times 10)$ were taken. They were photographed at the retina near the optic papilla, the middle part and the periphery. The RGCs were counted by Image-Pro Plus 6.0 image processing software, and the mean value was obtained $[17,32,33]$.

\section{RITC tracing optic nerve and frozen section preparation}

After injection of $2 \mu$ RITC (R1755-100MG, Sigma Company, USA) in the vitreous body and perfusion with 4\% PFA-PBS, the optic nerve was removed from the rats surviving 2 days after injection, fixed in 4\% PFA-PBS for a day, dehydrated with 30\% sucrose, embedded with OCT, and sliced into $7-\mu \mathrm{m}$ longitudinal sections using the cryostat microtome (Leica CM2016, Germany). The distal axon of the injured optic nerve was observed under the fluorescence microscope after glycerol carbonate mounting, and photographed with Image-Pro 6 image processing software in the front region of chiasm between $1 \mathrm{~mm}$ and $2 \mathrm{~mm}$. The number of RITC tracing axons was counted. 


\section{HE staining}

After routine perfusion of the heart with 4\% PFA-PBS, the eyeballs were fixed in 4\% PFA-PBS for one day. After water wash overnight, the eyeballs were dehydrated in ascending series of ethanol, cleared in xylene, and embedded in paraffin. Then, the paraffin sections were continuously sliced into $5 \mu \mathrm{m}$ sections using UltraThin Semiautomatic Microtome (Leica RM2016, Germany). After 2-min alcohol gradient dehydration, 10-min hematoxylin staining, 15-s 75\% hydrochloric acid ethanol differentiation, 15-s eosin staining, and 10-min xylene clearance, the slices were sealed with neutral balsam. Four slices of the retina were prepared for each animal and observed under the light microscope (BH-2, Olympus). The number of RGC layer cells in the retina was counted, and the mean value was statistically analyzed.

\section{Immunohistochemical staining}

After anesthesia and perfusion with 4\% PFA-PBS until the whole body became stiff, the left eyeball of each rat was removed, fixed in $4 \%$ PFA-PBS, embedded with paraffin, and sliced to $5-\mu \mathrm{m} \mathrm{sec}-$ tions. After antigen repair of the slices with citric acid buffer, the membrane was ruptured with $0.4 \%$ Triton X-100 to eliminate endogenous peroxidase with $0.3 \% \mathrm{H}_{2} \mathrm{O}_{2}$-PBS at room temperature. Then, the slides were washed and incubated overnight at $4^{\circ} \mathrm{C}$ with $\gamma$-synuclein (1:300, Abcam, Cambridge, United Kingdom), knowing that $\gamma$-synuclein is a specific marker molecule of RGCs used to assess RGC survival [34]. Then, a biotinylated goat secondary antibody (1:200, Boster, China) was covered on the section and incubated at $37^{\circ} \mathrm{C}$ for $30 \mathrm{~min}$. After washing with PBS, SABC enzyme reagent was placed at $37^{\circ} \mathrm{C}$ for $30 \mathrm{~min}$, then for $\mathrm{DAB}(1: 50$, Boster, China) reaction for $3 \mathrm{~s}$. Five fields of each retina section were observed under the microscope $(100 \times)$ after sealing, and four sections per eye were calculated and averaged.

\section{Immunofluorescence staining}

Four weeks after AAV2-Pim-1 ( $n=4)$ injection, frozen sections of the rat eyeball were made according to the above methods. The slices were dried, washed three times with PBS, pre-treated with $0.4 \%$ Triton $\mathrm{X}-100$ for $10 \mathrm{~min}$ at room temperature, soaked in blocking buffer (5\% donkey serum, 0.4\% Triton X-100, 1 h, room temperature), and incubated with primary rabbit antibodies $\gamma$-synuclein (1:300, Abcam) and mouse antibodies glial fibrillary acidic protein (GFAP, 1:200, CST, Boston, USA) respectively diluted in $5 \%$ donkey serum $+0.4 \%$ Triton $\mathrm{X}$ - 100 using a modified protocol with incubation overnight at room temperature. Subsequently, the slides were placed in corresponding donkey anti rabbit fluorescent secondary antibody cy3 (1:200, Jackson Immuno, USA) and donkey anti mouse fluorescent secondary antibody cy3 (1:200, Jackson Immuno) at room temperature for 1 h, stained with DAPI, and observed under the DMI8 fluorescence microscope (Germany Leica Company). The retinal flat mounts of the eyeball from four rats of AAV2-Pim-1 group were treated according to the above methods. After being soaked in the blocking buffer for $1 \mathrm{~h}$ at room temperature, the retinas flat mounts were incubated overnight at $4{ }^{\circ} \mathrm{C}$ with the primary mouse polyclonal antibody against syntaxin (HPC-1, SC-12736, 1:50, Santa Cruz Biotechnology, Dallas, USA). A biotinylated donkey secondary antibody (1:200, Jackson Immuno) was placed on the retina and incubated at $4{ }^{\circ} \mathrm{C}$ overnight. Images at $400 \times$ magnification were observed and captured by using a laser confocal microscope (Germany Leica Company) and analyzed using Adobe Photoshop CS3 software after DAPI nuclear dyeing.

\section{TdT-mediated dUTP Nick-End Labeling (TUNEL)}

The paraffin sections of the eyeball in the four groups $(n=6$ in each group) were baked at $60^{\circ} \mathrm{C}$ for $2.5 \mathrm{~h}$, dewaxed routinely, placed in $0.3 \% \mathrm{H}_{2} \mathrm{O}_{2}$-PBS and proteinase $\mathrm{K}$, and washed with TBS for $5 \mathrm{~min} \times 3$. Each section was added with $1 \mu \mathrm{l}$ TDT, $1 \mu \mathrm{l}$ DIG-dUTP and $18 \mu$ labeling buffer, incubated in the wet box at $37^{\circ} \mathrm{C}$ for $2 \mathrm{~h}$ and then with $50 \mu \mathrm{l}$ serum at room temperature for $30 \mathrm{~min}$ without washing. After addition of $50 \mu \mathrm{l}$ anti-digoxin antibody, the section was again incubated at $37^{\circ} \mathrm{C}$ for $30 \mathrm{~min}$, washed with TBS, added with $50 \mu \mathrm{SABC}$, incubated at $37^{\circ} \mathrm{C}$ for $30 \mathrm{~min}$, and subjected to DAB reaction for $3 \mathrm{~s}$. After hematoxylin counterstaining, xylene transparent and neutral balata sealing, the four retina slices were finally taken from each animal and observed under a light microscope. The number of apoptotic cells in the full-length RGC layer of the retina was counted, and the mean value was statistically analyzed.

\section{Quantitative real time polymerase chain reaction (qRT- PCR)}

Four weeks after intravitreal injection of $2 \mu \mathrm{lNS}$, AAV2-GFP or AAV2-Pim-1 in the three non-ONC groups ( $n=6$ in each group), the rats were dislocated and sacrificed under anesthesia. The retina was removed under the anatomical microscope and placed in $500 \mu \mathrm{l}$ lysate. Total RNA of the retina in each group was extracted according to the RNA Extraction Kit (Solarbio R1200, Beijing, China) and the concentration was measured by enzyme-labeled instrument. The cDNA was synthesized using reverse transcriptase (Takara RR037A, Japan) under the following conditions: $37^{\circ} \mathrm{C}, 15$ $\min ; 85^{\circ} \mathrm{C}, 5 \mathrm{~s} ; 4^{\circ} \mathrm{C}, 5 \mathrm{~min}$. The primer sequences of the objective and reference genes were designed from the Genbank database and analyzed by the biological software DNAstar. The primer sequences are as follows: Pim-1: forward, 5'-TCCAGGGAAGAGAGAGCTT- 
Table 2. Primary antibodies and origin of the species for Western blotting

\begin{tabular}{|c|c|c|c|c|}
\hline Primary antibody & Cat & Species origin & Dilutions & Manufacturer \\
\hline Stat3 & \#9139 & Mouse & $1: 1,000$ & CST (Boston,USA) \\
\hline p-Stat3 & \#9134 & Rabbit & $1: 1,000$ & CST (USA) \\
\hline Aktl & $\# 2938$ & Rabbit & $1: 1,000$ & CST (USA) \\
\hline p-Aktl & $\mathrm{ab} 81283$ & Rabbit & $1: 5,000$ & Abcam (Cambridge,UK) \\
\hline Akt2 & $\# 3063$ & Rabbit & $1: 1,000$ & CST (USA) \\
\hline p-Akt2 & \#8599 & Rabbit & $1: 1,000$ & CST (USA) \\
\hline Erk1/2 & \#4695 & Rabbit & $1: 1,000$ & CST (USA) \\
\hline $\mathrm{p}$-Erk1/2 & $\# 4370$ & Rabbit & $1: 1,000$ & CST (USA) \\
\hline SOCS1 & $\# 3950$ & Rabbit & $1: 1,000$ & CST (USA) \\
\hline SOCS3 & ab16030 & Rabbit & $1: 1,000$ & Abcam (UK) \\
\hline Caspase 3 & \#9665 & Rabbit & $1: 1,000$ & CST (USA) \\
\hline Cleaved caspase 3 & \#9664 & Rabbit & $1: 1,000$ & CST (USA) \\
\hline Bad $\quad \mathrm{r}$ ( & ab32445 & Rabbit & $1: 2,000$ & Abcam (UK) \\
\hline Bax & $\# 14796$ & Rabbit & $1: 1,000$ & CST (USA) \\
\hline BIII-tubulin & ab18207 & Rabbit & $1: 1,000$ & Abcam (UK) \\
\hline GAP-43 & $\mathrm{ab} 75810$ & Rabbit & $1: 5,000$ & Abcam (UK) \\
\hline CXCR4 & ab124824 & Rabbit & $1: 100$ & Abcam (UK) \\
\hline Met & sc- 8057 & Mouse & $1: 200$ & Santa Cruz (Santa Cruz, Bolivia) \\
\hline $\mathrm{c}-\mathrm{Myc}$ & ab32072 & Rabbit & $1: 5,000$ & Abcam (UK) \\
\hline 4E-BP1 & $\# 9644$ & Rabbit & $1: 1,000$ & CST (USA) \\
\hline Pim-1 & sc-7857 & Goat & $1: 200$ & Biotech Well (Shanghai,China) \\
\hline GAPDH & wb0197 & Mouse & $1: 2,000$ & CST (USA) \\
\hline
\end{tabular}

GTC-3' and reverse, 5'-TCATTTCTGTCCCTGCATCGT-3'; GAPDH: forward, 5'-GCCATCAACGACCCCTTCAT-3' and reverse, 5'-TTCACACCCATCACAAACA-3'. On the basis of the configured SYBR Green reaction system (Takara RR820A, Japan), real-time PCR was performed. The objective gene expression was calculated by the relative quantitative statistical method $\left(2^{-\Delta \Delta \mathrm{Ct}}\right)$ [35]. The rats from the four groups were intravitreally injected with $2 \mu \mathrm{l}$ saline, saline, AAV2-GFP and AAV2-Pim-1 respectively. Two weeks after successful establishment of the ONC model, the expression of Pim-1 mRNA in the retina was detected by Real-time PCR.

\section{Western blotting}

Four weeks after intravitreal injection of $2 \mu \mathrm{l} \mathrm{NS}$, AAV2-GFP and AAV2-Pim- 1 in the three non-ONC groups $(n=6)$, the retina was removed. The rat eyeballs from the four groups were injected with $2 \mu \mathrm{l}$ saline, saline, AAV2-GFP and AAV2-Pim-1 respectively, and the ONC model was established after 4 weeks, then the retina was taken out 2 weeks after ONC. Total protein of the retina was extracted and the concentration was measured after addition of RIPA cracking fluid. The protein was electrophoresed by SDSPAGE gel and transfered to the polyvinyl fluoride (PVDF) membrane. The membrane was then incubated in 5\% bovine serum albumin (BSA) at room temperature for $2 \mathrm{~h}$, added with the primary polyclonal antibodies of Pim- 1 and GAPDH, and incubated at $4{ }^{\circ} \mathrm{C}$ overnight. After washing the membrane with TBST, biotinylated secondary antibodies rabbit anti goat $\operatorname{IgG}(1: 2,000$, Biotech Well) and sheep anti mouse $\operatorname{IgG}(1: 2,000$, Biotech Well) were added to the membrane and incubated at room temperature for $2 \mathrm{~h}$. Other molecules included the key signal pathway-related molecules Stat3, p-Stat3, Akt1, p-Akt1, Akt2, p-Akt2, Erk1/2, p-Erk1/2, SOCS1 and SOCS3; cell apoptosis-related molecules Caspase 3, Cleaved caspase 3, Bad and Bax; axonal regeneration-related molecules BIIItubulin and GAP-43; tumor invasion-related molecules CXCR4, Met and c-Myc; and eukaryotic cell translation initiation factor 4E-BP1 (Table 2). Biotinylated secondary antibodies were added to the membrane accordingly. The operating method of these molecules was the same as previously described. After Gel imaging for fluorescence by chemiluminescence, the banding was analyzed quantitatively using the Image Pro Plus 6.0 software.

\section{Pupillary light reflex}

Two weeks after ONC, the animals in the four groups $(n=6)$ were anesthetized with $10 \%$ chloral hydrate $(0.35 \mathrm{ml} / 100 \mathrm{~g}$ per rat) via i.p. injection to avoid inhibition of the pupil light reflection [36]. The rats were placed in the darkroom for $30 \mathrm{~min}$, and the eye without surgery was protected from light by using a piece of silver paper. The surgical eye was observed under the stereomicroscope (SZX12, Olympus), and stimulated with a light source (LG-PS2, Olympus). The maximum and minimum diameters of the pupil on the surgical side were recorded using the screen video expert software (V2012, China) for 5 min each time, and each animal was measured at least 4 times. The recorded responses were replayed on the video frame by frame, and pupil images were analyzed by using batch processing in Photoshop (CS3 extended, Adobe Sys- 
tem, CA) [37]. The minimum/maximum pupil diameter ratio was calculated by quantitative analysis.

\section{Flash visual evoked potential (FVEP)}

Two weeks after ONC, flash visual evoked potential was induced to record the latency and amplitude of $\mathrm{P}$ wave using the biological signal processing system (BMLab-4.0, China). The head of the animal was depilated to expose the skull under anesthesia. A calvarial defect was created near the right occipital lobe of the cerebral cortex by using a cranium drill, avoiding injury to the dura mater encephali. The red electrode was connected to the silver pole, the black electrode to the ground, and blue electrode to the contralateral skin of the eyeball. The suspended silver electrode was moved to the site of measurement in a manner that there was a sense of breakthrough without actually penetrating the dura mater encephali. Finally, the parameters were fed into the computer software to conduct the sample test at $16 \mathrm{~ms}$ and $32 \mathrm{~ms}$.

\section{Statistical analysis}

All quantitative data are expressed as mean \pm standard deviation (SD), and the statistical analysis was carried out by using SPSS 18.0 software. Comparison of all data was performed using single factor analysis of variance, and pairwise comparison was performed with Student-Newman-Keuls (SNK) test. Data that did not satisfy the homogeneity of variance were transformed into a normal distribution and then analyzed by variance test. Values of $p<0.05$ were regarded to be statistically significant.

\section{RESULTS}

\section{Infection of the rat retina with AAV2-Pim-1}

Four weeks after AAV2-Pim-1 injection, retinal flat mounts showed that AAV2-Pim-1 successfully expressed enhanced green fluorescence protein (EGFP) in many retinal cells, nerve fibers, and nuclei in particulars, and some cytoplasm; the percentage of infected cells was 50\% (Fig. 1A1 A3). Subsequent $\gamma$-synuclein immunofluorescence staining showed that double-labeled cells accounted for $71 \%$ of RGCs, indicating that AAV2-Pim-1 infected $71 \%$ of RGCs (Fig. 1B1 B4). GFAP specifically labeled astrocytes, the green fluorescence of GCL and the red fluorescence of GFAP almost did not overlap, indicating that AAV2-Pim-1 almost did not infect astrocytes (Fig. 1C1 C4). HPC-1 specifically labeled the membrane of amacrine cells, and the green fluorescence on the retina overlapped with the red fluorescence of HPC-1, indicating that a small number of amacrine cells were infected by AAV2Pim-1 (Fig. 1D1 D3).

\section{AAV2-mediated overexpression of Pim-1 in the rat normal retina and $\mathrm{ONC}$ retina}

Real-time PCR and Western blotting were performed to detect Pim-1 mRNA and protein expressions in the AAV2-Pim-1-injected rat retina. Four weeks after injection, no significant difference in Pim-1 mRNA expression was observed between Sham and AAV2GFP groups; Pim-1 mRNA expression in the retina of AAV2Pim-1 group was about 6.61 times as high as that in AAV2-GFP group, indicating that Pim-1 mRNA expression was obviously up-regulated (Fig. 2A). Meanwhile, there was no significant difference in Pim-1 protein expression between Sham and AAV2-GFP groups, demonstrating that AAV2-GFP did not affect the Pim1 protein expression in the retina, and the Pim-1 protein in the retina of AAV2-Pim-1 group was about 2.29 times as high as that in AAV2-GFP group, suggesting that the Pim-1 protein expression was obviously up-regulated (Fig. 2B).

An optic nerve injury model was made 4 weeks after intravitreal injection of NS, AAV2-GFP and AAV2-Pim-1. Two weeks after ONC, the Pim- 1 mRNA and protein expressions in the retina were detected. The result of Real-time PCR showed that there was no significant difference in Pim-1 mRNA expression between AAV2GFP group and Injury group; the Pim-1 mRNA expression in AAV2-Pim-1 group was about 2.28 times as high as that in Injury group and AAV2-GFP group (Fig. 2C). The result of Western blotting showed no significant difference in Pim-1 protein expression between Injury group and AAV2-GFP group, while the Pim-1 protein expression in AAV2-Pim-1 group was significantly lower than that in Sham group, probably due to delayed translation of mRNA into protein, but significantly higher than that in Injury group and AAV2-GFP group, and about 5.27 times as high as that of AAV2GFP group (Fig. 2D).

\section{Neuroprotection and axonal regeneration mediated by AAV2-Pim-1 after axonal trauma}

The paraffin embedded and haematoxylin \& eosin (HE) stained rat eyeball sections were observed in terms of the number and morphology of cells on GCL (Fig. 3A). Two weeks after optic nerve injury, the number of GCL cells in Injury group was significantly lower than that in Sham group $(\mathrm{p}<0.001)$, and there was no statistically significant difference between Injury group and AAV2-GFP group, indicating that the number of GCL cells in the rats retina was not significantly affected by AAV2-GFP injection. However, the number of GCL cells in AAV2-Pim-1 group was about 1.52 times as high as that in AAV2-GFP group (Fig. 3B), suggesting that Pim-1 overexpression could increase the number of GCL cells.

The effect of Pim-1 overexpression on RGC survival after Pim-1 overexpression was observed by $\gamma$-synuclein immunohistochemi- 


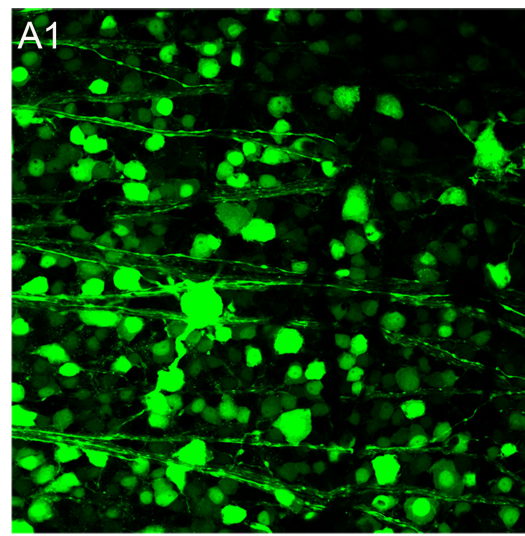

\section{A2}
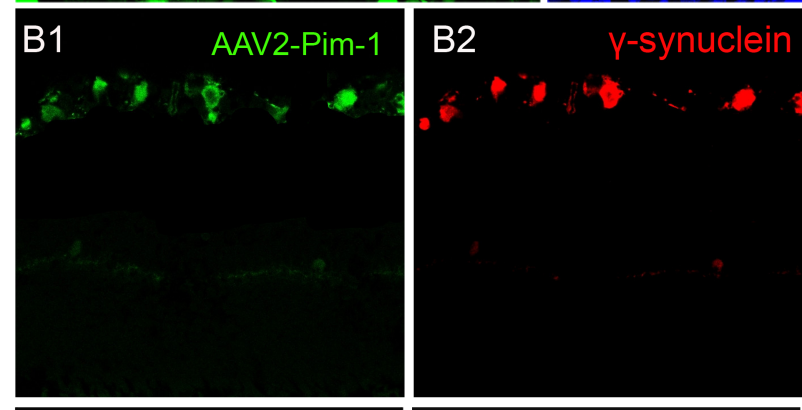

C1

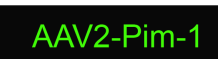

\section{C2} $a$ $30 .+10$

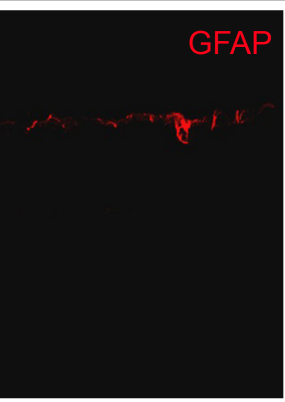

B3
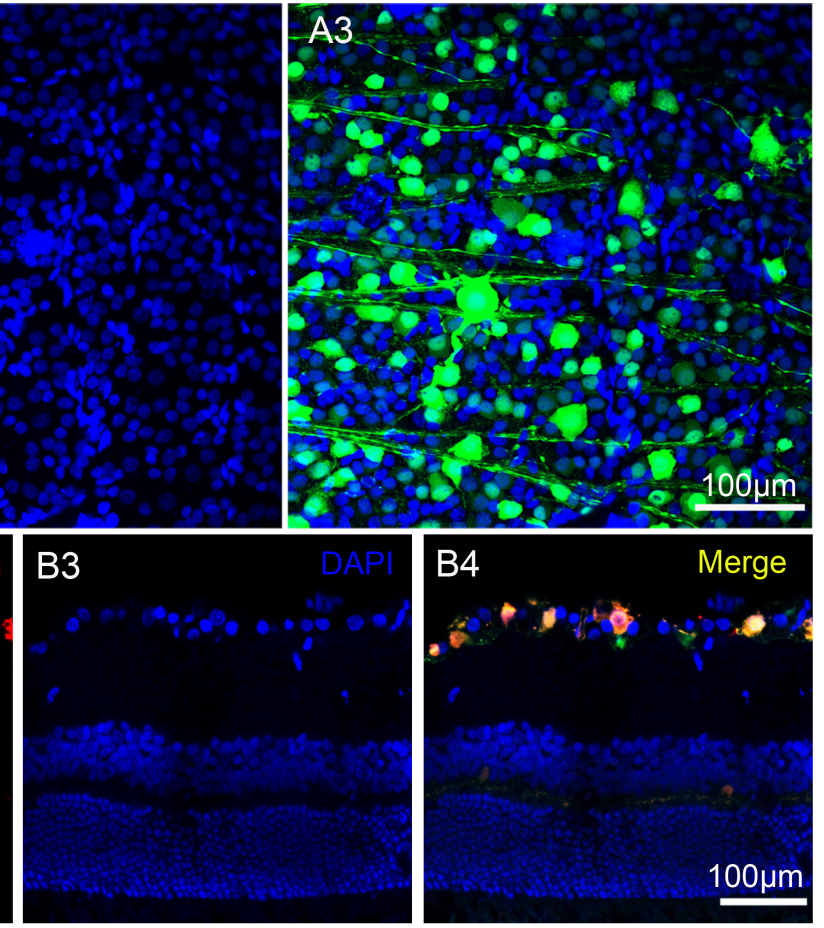

\section{C3}

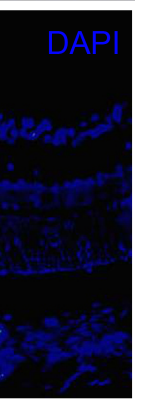

C4

Merge

an achen.

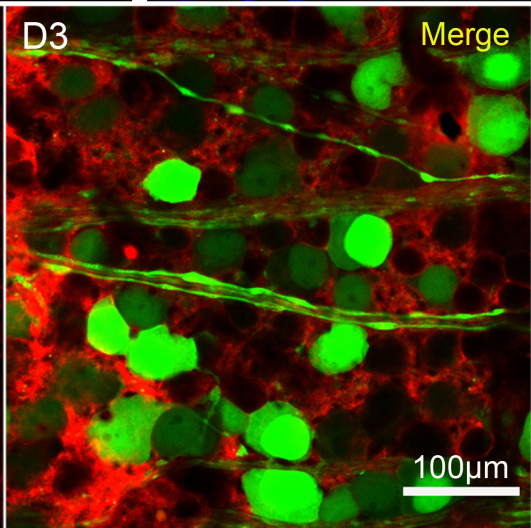

Fig. 1. Retinal flat mounts and cryostat sections of the eyeball in the AAV2-Pim-1 infected rat were stained with immunofluorescence histochemistry. (A1, B1, C1, D1) AAV2-Pim-1 infected the retina and RGCs. (A2, B3, C3) Blue staining indicates DAPI labeled nuclei. (A3, B4, C4, D3) AAV2-Pim-1 was co-located with $\gamma$-synuclein, GFAP or HPC-1. Green fluorescence for AAV2-Pim-1 and red immunostaining for $\gamma$-synuclein, GFAP or HPC-1. Scale bar $=50 \mu \mathrm{m}, \mathrm{n}=4$.

cal staining and FITC-CTB tracing (Fig. 3C and Fig. 3E). Two weeks after ONC, the number of surviving RGC in Injury group was significantly lower than that in Sham group $(\mathrm{p}<0.001)$, and there was no statistically significant difference between Injury group and AAV2-GFP group. Pim-1 overexpression increased the survival of RGCs in AAV2-Pim-1 group, which was 1.67 times as 
A

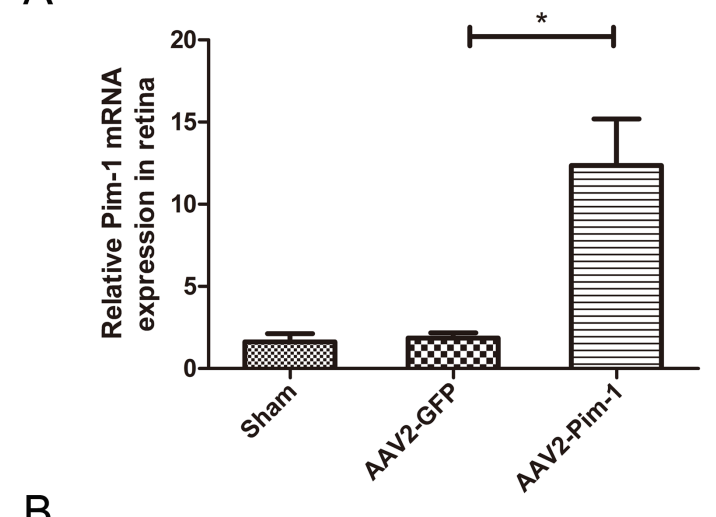

B

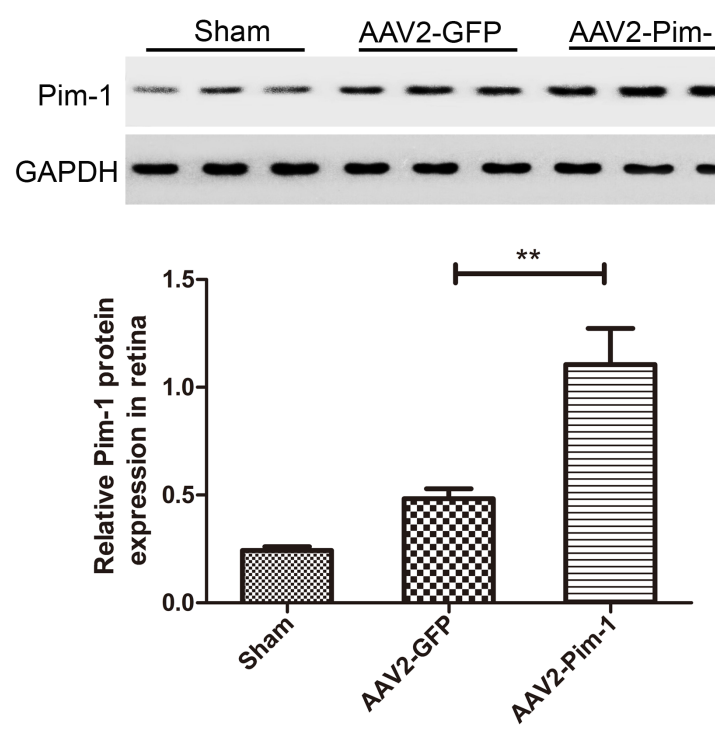

C

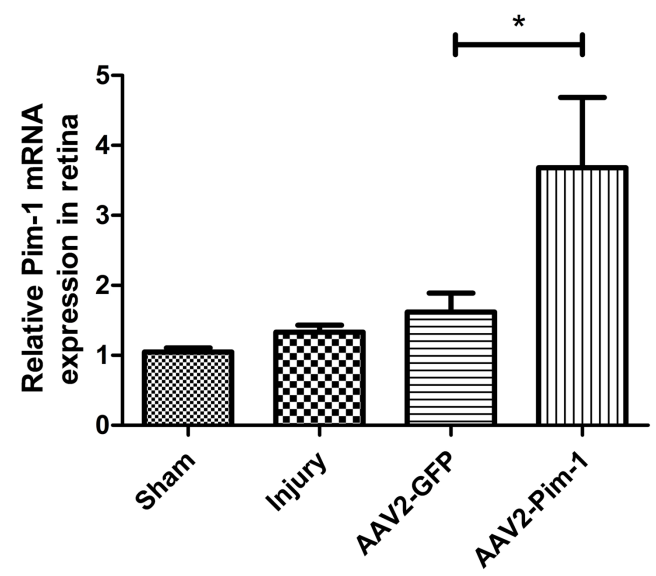

D
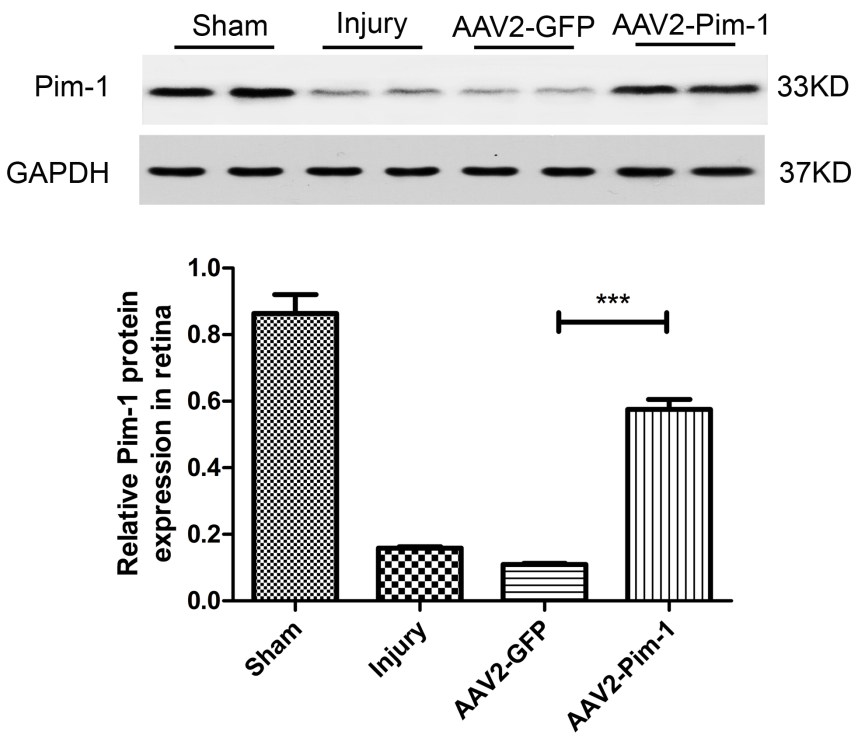

Fig. 2. Pim-1 mRNA and protein overexpressions in the retina after AAV2-Pim- 1 infection in the normal rat retina (A, B) and in the retina 2 weeks after ONC (C, D) in vivo. (A, C) Detection of Pim-1 mRNA expression in the retina by Real-time PCR in each group. (B, D) Detection of Pim-1 protein expression in the retina by Western blotting in each group. The relative protein levels in Y-axis was quantified by dividing the gray value of the experimental groups by the gray value of GAPDH. Compared with the AAV2-GFP group, ${ }^{*} \mathrm{p}<0.05,{ }^{* *} \mathrm{p}<0.01,{ }^{* * *} \mathrm{p}<0.001 ; \mathrm{n}=6$.

high as that in AAV2-GFP group (Fig. 3D) detected by $\gamma$-synuclein immunohistochemical staining, and about two times as high as that in AAV2-GFP group detected by FITC-CTB tracing (Fig. 3F). These morphological changes indicated that Pim-1 overexpression played a significant neuroprotective role in promoting the survival of RGCs after ONC.

Apoptosis of GCL cells in paraffin-embedded retina sections was observed by TUNEL staining. DAB brown-yellow staining of the nuclei represents cell apoptosis (Fig. 4A). Quantitative analysis showed that TUNEL-positive cells decreased by 1.75 times in the AAV2-Pim-1-injected eyes versus the control AAV2-GFP-injected eyes, and increased in Injury group compared with the Sham group. But there was no significant difference in cell apoptosis between AAV2-GFP group and Injury group (Fig. 4B). Pim-1 over- expression reduced the number of apoptotic cells in AAV2-Pim-1 group, indicating that Pim-1 overexpression exerted a protective effect on GCL cells.

\section{Axonal regeneration mediated by AAV2-Pim-1 after optic nerve injury}

RITC was used to trace the regenerative axons in the distal optic nerve $(0.2 \mathrm{~cm}$ distant from the optic chiasma) passing the injured sides in Sham, Injury, AAV2-GFP and AAV2-Pim-1 groups (Fig. $5 A)$. Two weeks after injury, the number of axons in the distal segment of the optic nerve in Injury group was significantly lower than that in Sham group $(\mathrm{p}<0.001)$, and there was no statistical significance versus AAV2-GFP group. Pim-1 overexpression increased the number of axons in AAV2-Pim-1 group, which was 
A

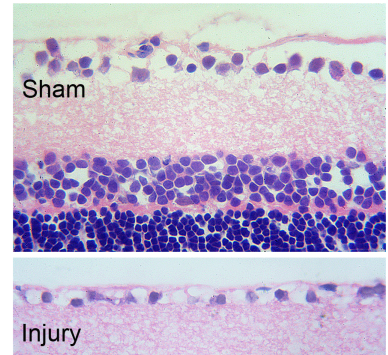

-
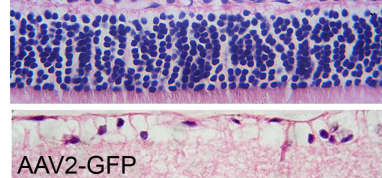

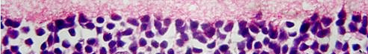
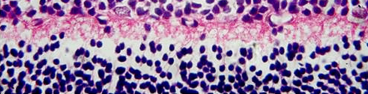

$\because \cdots \cdots+\cdots, \cdots, \cdot 0,0$ AAV2-Pim-1

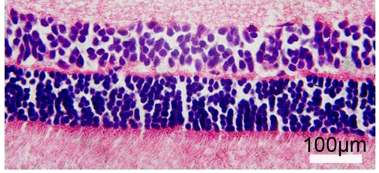

B

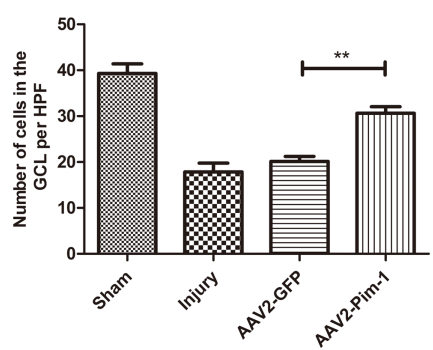

C
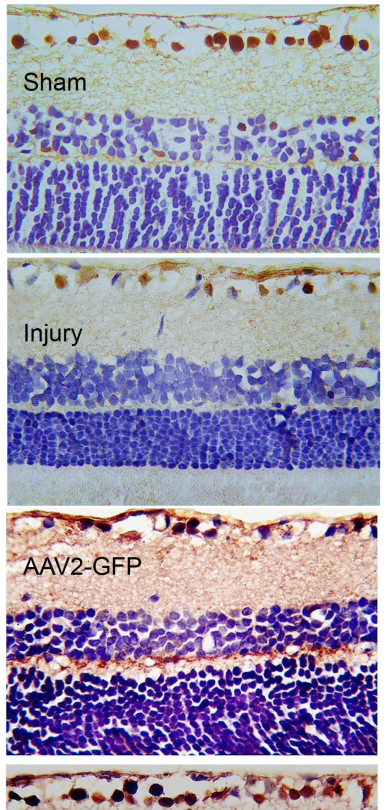

AAV2-Pim-1

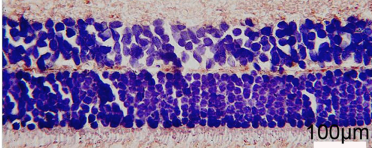

D

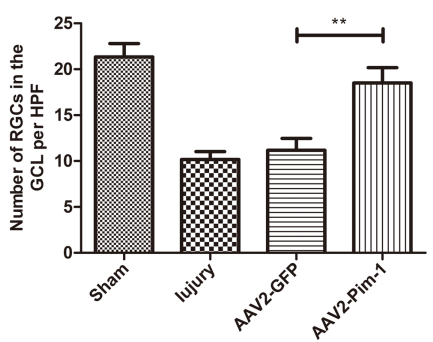

E
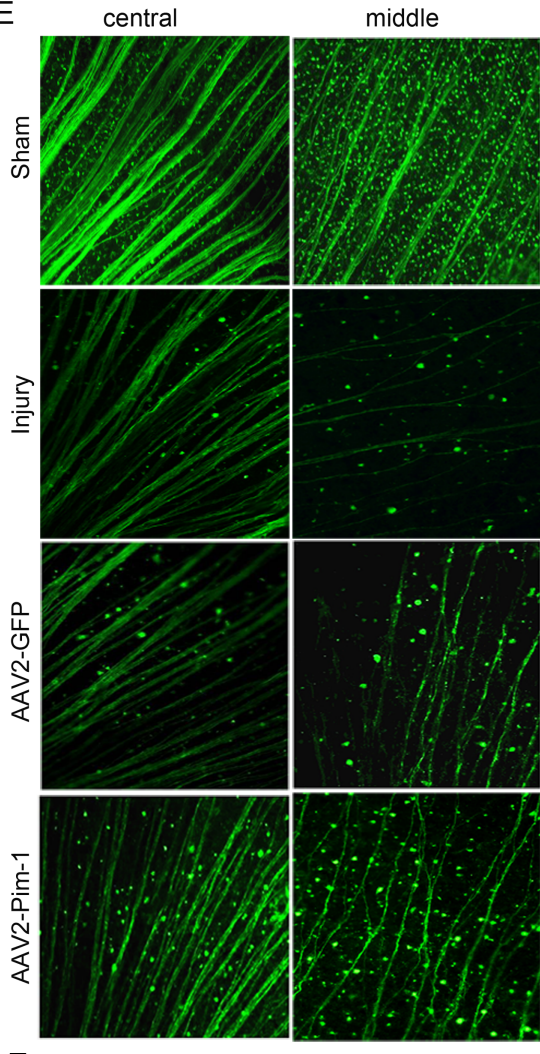

peripheral
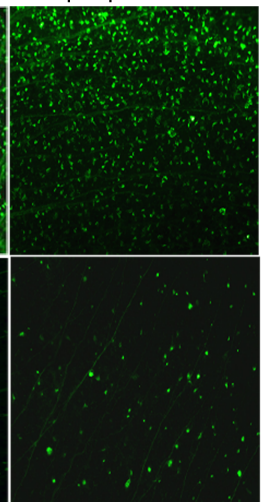

F

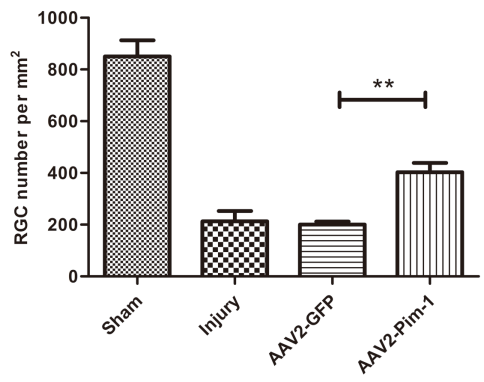

Fig. 3. HE staining, $\gamma$-synuclein immunohistochemical staining and FITC-CTB tracing to test survival of RGCs. (A, C and E) All staining of retinal sections 2 weeks after ONC, and $\gamma$-synuclein-positive RGCs were visualized in brown yellow, RGC density in the representative flat-mounted retina by FITC-CTB tracing to test survival of RGCs. (B, D and F) AAV2-mediated overexpression of Pim-1 showed a significant neuroprotective effect on RGCs. Compared with AAV2-GFP group, ${ }^{* *} \mathrm{p}<0.01 ; \mathrm{n}=6$.

significantly higher than that in Injury group and AAV2-GFP group $\left({ }^{*} \mathrm{p}<0.01\right.$, Fig. $\left.5 \mathrm{~B}\right)$, suggesting that Pim-1 overexpression could promote regeneration of axons of the RGCs after axonal trauma.

AAV2-Pim-1 improves the visual functional activity of RGCs following axonal injury

Visual function recovery was assessed by observation of the pupillary light reflex (Fig. 6A). Pim-1 overexpression significantly reduced the minimum/maximum pupil diameter ratio in AAV2Pim-1 group, and the diameter ratio decreased by about 2.4 times compared with that in Injury group and AAV2-GFP group, but there was no statistical difference between Injury and AAV2-GFP groups (Fig. 6B), suggesting that Pim-1 overexpression could reduce the pupil diameter ratio and promote visual function recovery.

FVEP was used to record the amplitude and latency of $\mathrm{P}$ wave (Fig. 6C). Two weeks after optic nerve injury, the amplitude of the $P$ wave in Injury group was significantly lower than that in Sham group $(\mathrm{p}<0.001)$. The amplitude of $\mathrm{P}$ wave in AAV2-GFP group was slightly increased as compared with that in Injury group $(\mathrm{p}<0.05)$, and the Pim-1 overexpression significantly increased the 
A
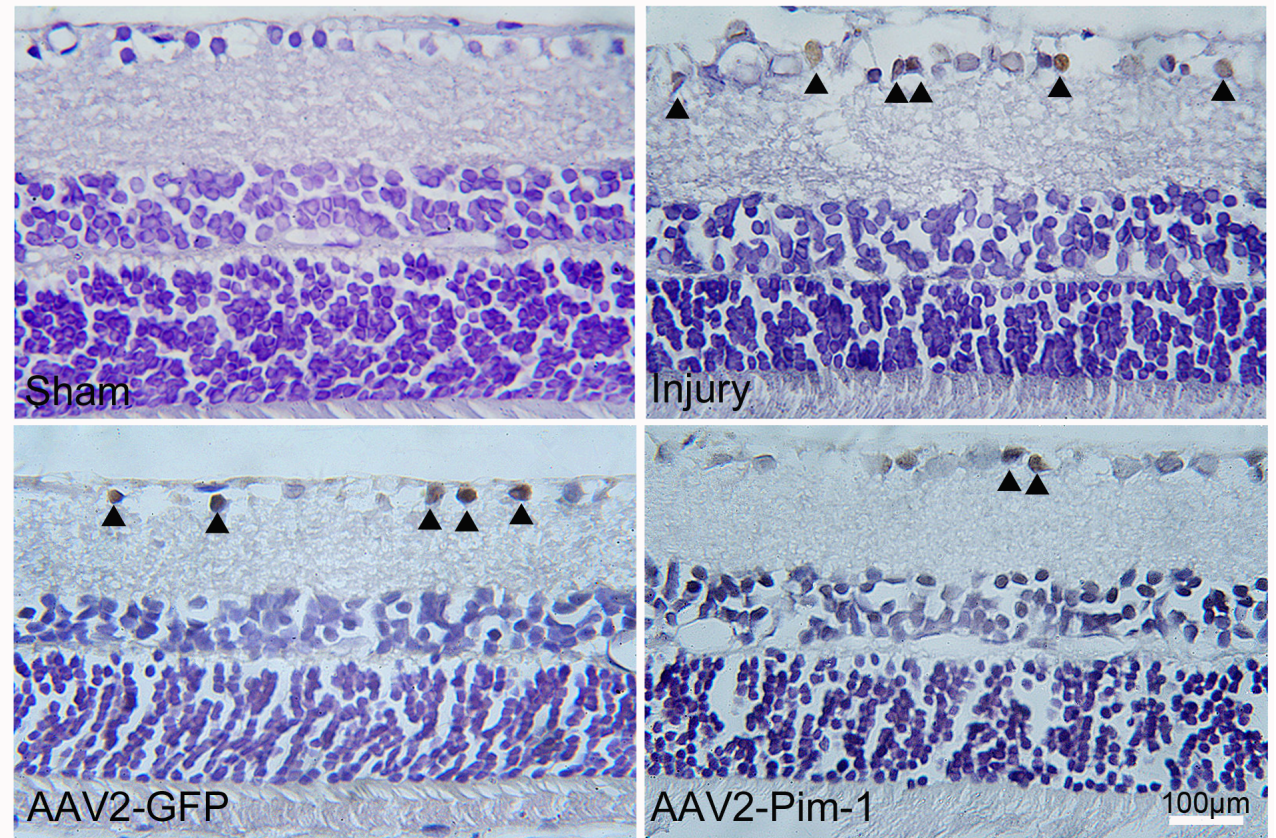

B

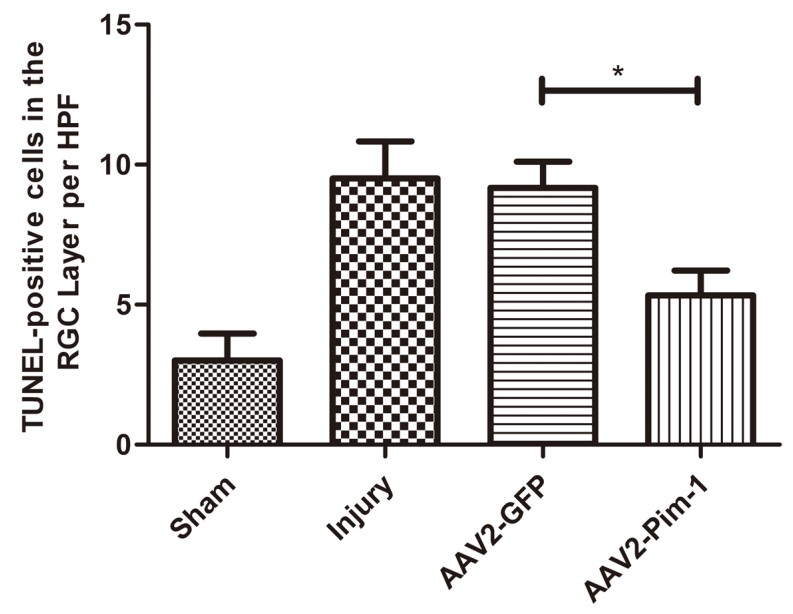

Fig. 4. AAV2-mediated delivery of Pim-1 in vivo decreased apoptosis of GCL cells by TUNEL staining. (A) TUNEL staining was performed, where brownyellow staining represents apoptotic cells (arrows). Scale bar $=100$ $\mu \mathrm{m}$. (B) Quantitative analysis of TUNEL-positive cells showed that Pim-1 overexpression reduced the number of apoptotic cells two weeks after ONC in AAV2-Pim-1 group. Compared with AAV2-GFP group, ${ }^{*} \mathrm{p}<0.05$; $\mathrm{n}=6$.

amplitude of $\mathrm{P}$ wave in AAV2-Pim-1 group as compared with that in Injury group and AAV2-GFP group (Fig. 6D). The latency of P wave in Injury group was significantly longer than that in Sham group $(\mathrm{p}<0.001)$, and there was no statistically significant difference between Injury group and AAV2-GFP group. The P wave latency in AAV2-Pim-1 group was significantly shorter than that in Injury and AAV2-GFP groups (Fig. 6E), suggesting that Pim1 overexpression could promote visual functional recovery by increasing the amplitude of $\mathrm{P}$ wave and shortening the latency of $\mathrm{P}$ wave.
AAV2-Pim-1 mediated expression of molecules of cell survival-and growth-related signaling pathways

To further confirm the beneficial effects of AAV2-Pim-1 on cell survival- and growth-related signaling pathways after ONC, the retina was examined for Stat3, p-Stat3, Akt1, p-Akt1, Akt2, p-Akt2, Erk1/2,p-Erk1/2, SOCS1 and SOCS3 protein expressions 2 weeks after ONC by Western blotting. Retinal protein lysate analysis showed that the expression of Stat3, p-Stat3, Akt1, p-Akt1, Akt2 and $\mathrm{p}-\mathrm{Akt} 2$ in the retina was increased after AAV2-Pim-1 injection compared with the control AAV2-GFP retina, and the expression of SOCS1 and SOCS3 in the retina of AAV2-Pim-1 group was downregulated as compared with that in AAV2-GFP group, 


\section{A}
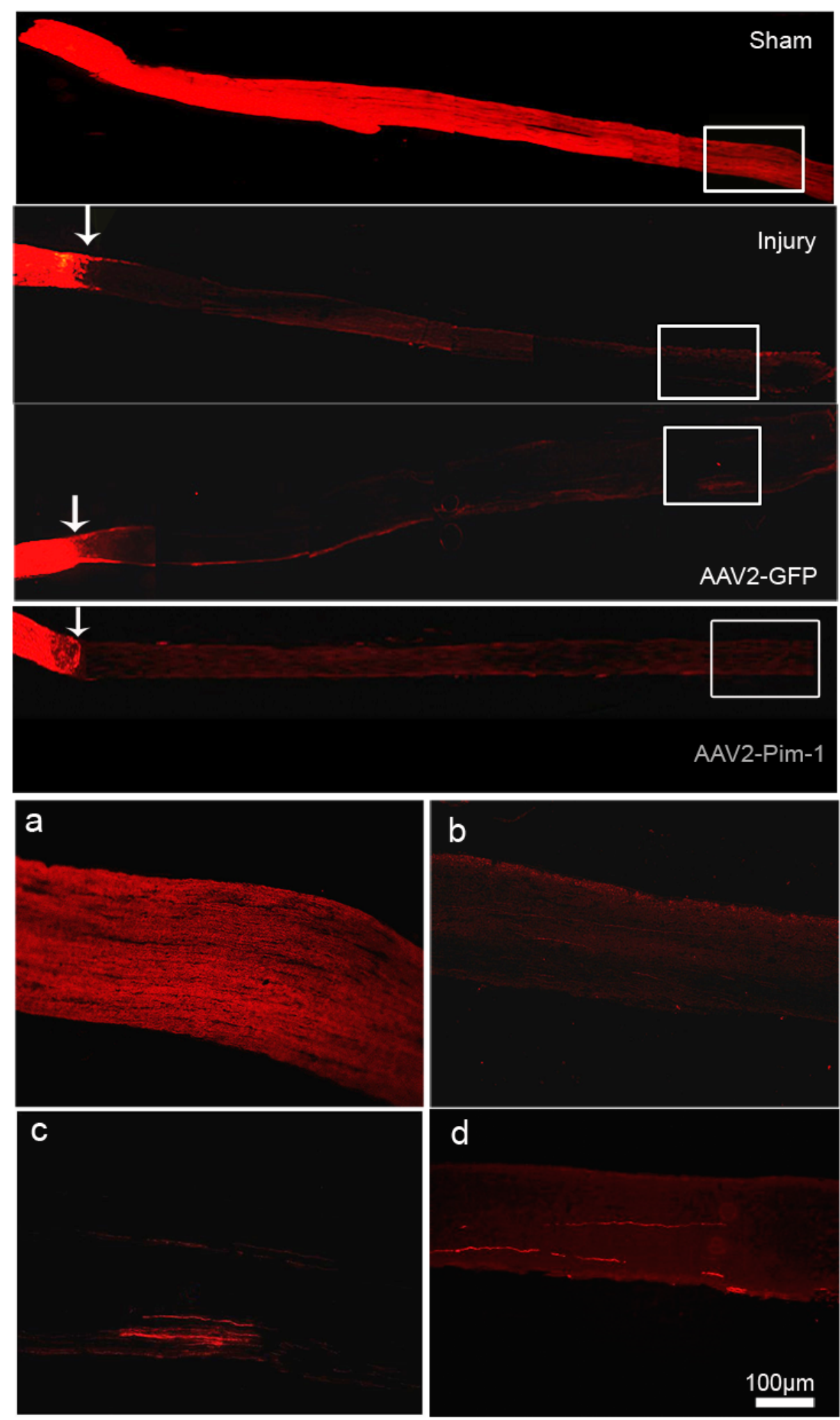

b 
B

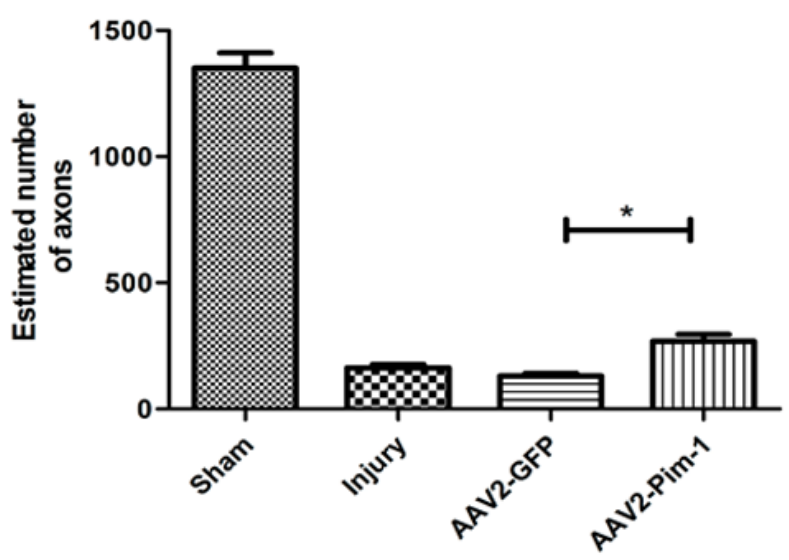

Fig. 5. Continued.

but there was no significant difference in the expression of Erk1/2 and $\mathrm{p}$-Erk1/2 protein in the retina of AAV2-GFP and AAV2Pim-1 group (Fig. 7A, B, E, F, G, H, M, N, O and P). Quantitative results of Western blotting in each molecule are shown in Table 3 and Fig. 7C, D, I, J, K, L, Q, R, S and T.

\section{Effects of Pim-1 overexpression on apoptosis- and survival- related proteins}

Western blotting was used to detect the protein expression of apoptosis-related molecules of Caspase 3, Cleaved caspase 3, Bad and Bax in the retina of the four rat groups (Fig. 8A, B, E and F). Quantification by densitometry of retinal lysates between the four groups for Caspase 3, Cleaved caspase 3, Bad and Bax molecules was exhibited in Table 4 and Fig. 8C, D, G and H. Pim- 1 overexpression significantly down-regulated the expression of Cleaved caspase 3, Bad and Bax. Compared with AAV2-GFP group, the difference was statistically significant. But overexpression of Pim1 had little effect on the expression of total Caspase 3 protein in rat retinas.

\section{AAV2-Pim-1 promotes the expression of axonal regenera-} tion-related proteins

Retinas were examined 2 weeks after injury for $\beta$ III-tubulin and GAP-43 expression by Western blotting. Analysis of the retinal protein lysates showed that the expression of $\beta$ III-tubulin and GAP-43 was increased in the retinas after AAV2-Pim-1 injection compared with AAV2-GFP retinas (Fig. 9A and B). Quantification of Western blotting showed a significant increase $(\mathrm{p}<0.01)$ in $\beta I I I-$ tubulin expression in AAV2-Pim-1-treated retinas compared with that in AAV2-GFP controls (Fig. 9C). The regenerative marker GAP-43 also showed a significant increase $(\mathrm{p}<0.05)$ in AAV2Pim-1 group compared with AAV2-GFP group (Fig. 9D).

\section{Pim-1 overexpression has no significant effect on the} expression of tumor invasion-related proteins

Western blotting was used to detect the expression of tumor invasion-related proteins CXCR4, Met and c-Myc in the retina of the four rat groups (Fig. 10A, B and C). Analysis of the tumor invasion-related proteins revealed that Pim-1 had no significant effect on CXCR4, Met and c-Myc expression in the retinas (Fig. 10D, E and F).

\section{AAV2-Pim-1 promotes the expression of eukaryotic cell translation initiation factor}

Western blotting was used to detect the expression of translation initiation factor $4 \mathrm{E}-\mathrm{BP} 1$ in rat retinal cells. After ONC, the expression of 4E-BP1 protein in retinal cells in Injury and AAV2-GFP groups was significantly lower than that in Sham group $(\mathrm{p}<0.05)$, and the protein was up-regulated after Pim-1 overexpression in the retina, compared with Injury group and AAV2-GFP group $(\mathrm{p}<0.01)$ (Fig. 11).

\section{DISCUSSION}

\section{Neuroprotection and axonal regeneration mediated by AAV2-Pim-1 after axonal trauma}

The intrinsic regeneration ability of RGCs is the survival ability of damaged RGCs and the re-growth ability of their axons to specific target cells $[38,39]$. Weakening of the intrinsic regeneration ability of RGCs is a key factor for the failure of optic nerve regeneration. Pim-1 acts as a common downstream effector for cell survival and growth signaling pathways [19] by regulating the plasticity, excitability, release of neurotransmitters, and the survival and apoptosis of damaged neurons [26, 40, 41]. In embryonic mice, Pim-1 distributes in the visual cortex of the occipital lobe, 
A

at the start
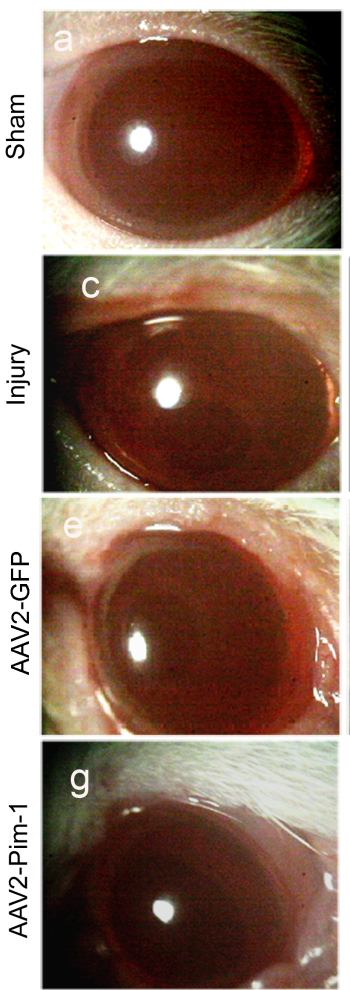

B

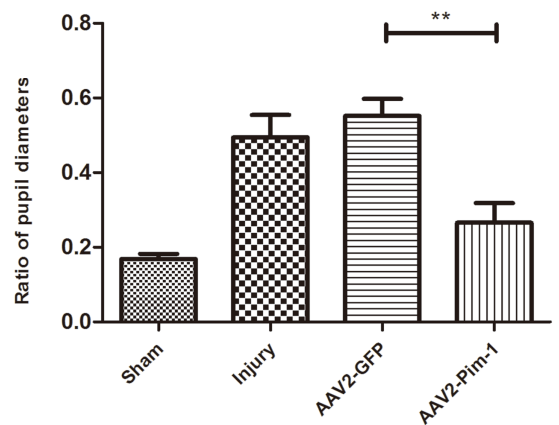

at the end
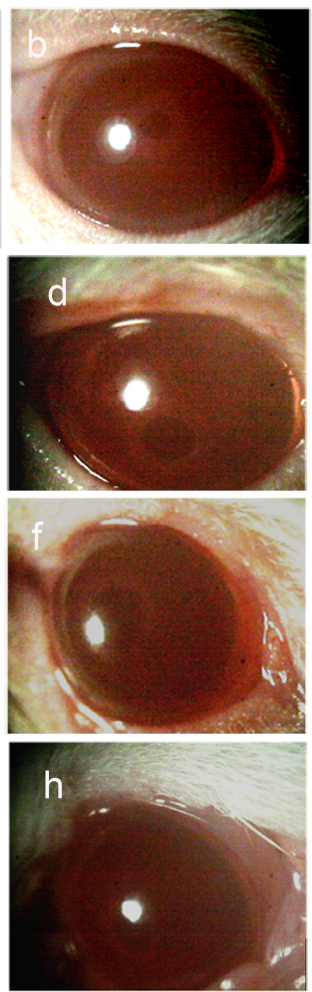

D
C

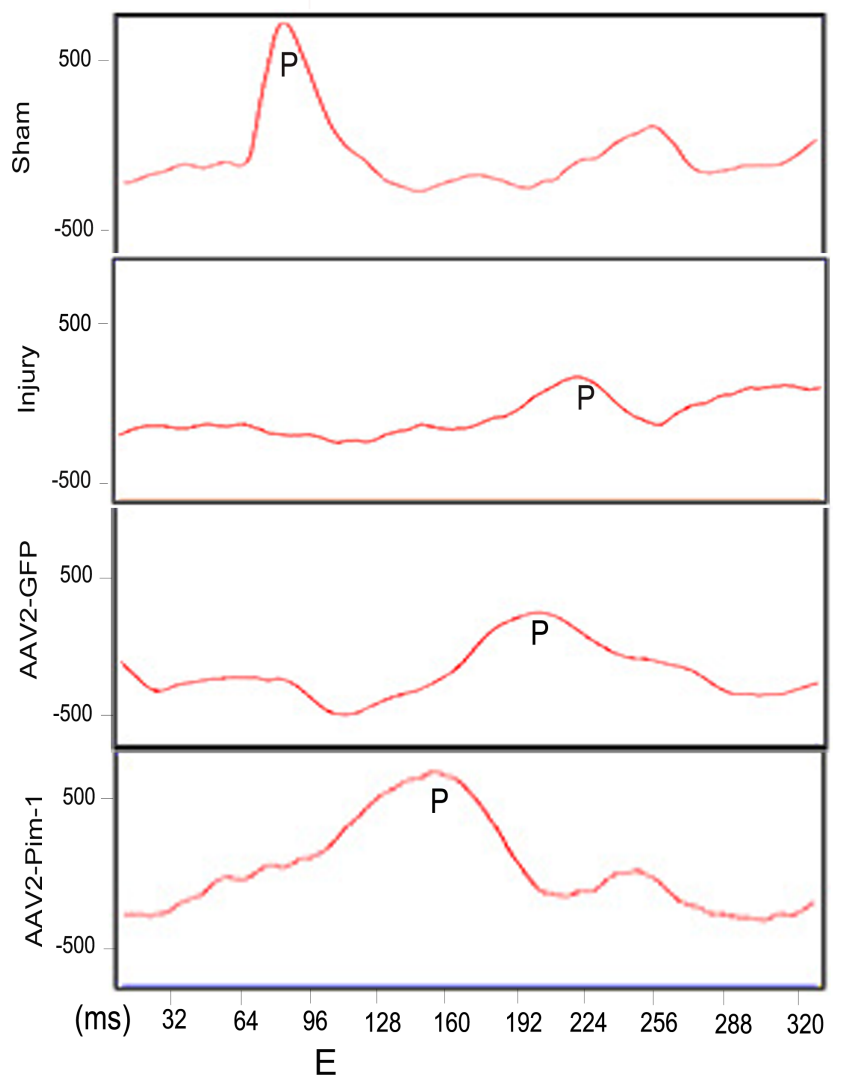

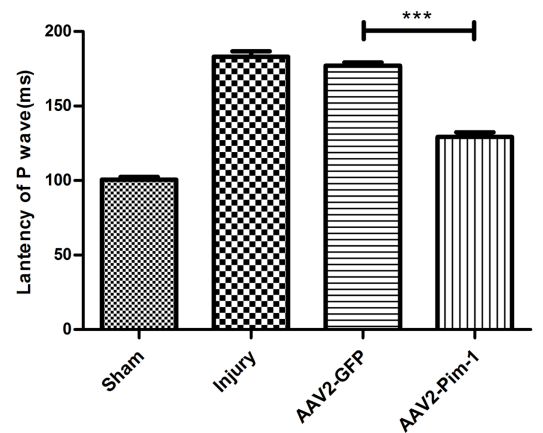

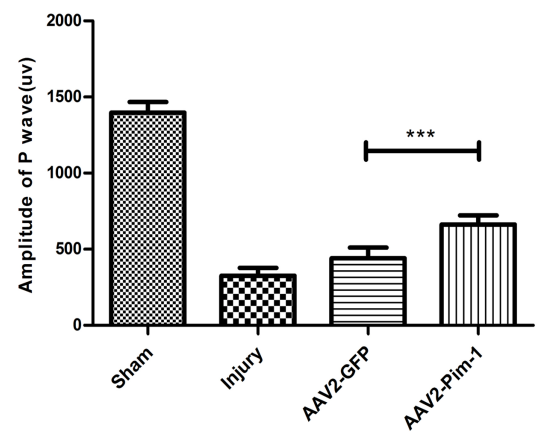

Fig. 6. The visual function is increased in vivo after intravitreal injection of AAV2-Pim-1. (A) The minimum and maximum pupil diameters were recorded in each group by pupil light reflex. Pupils were at the start (a, c, e and g) and end (b, d, f and h) of the stimulus. (B) The minimum/maximum pupil diameter ratio in Injury and AAV2-GFP was larger than that in Sham group, but the ratio in AAV2-Pim-1 group after Pim-1 overexpression was lower than that in Injury group and AAV2-GFP group. Compared with the AAV2-GFP group, ${ }^{\star *} \mathrm{p}<0.01 ; \mathrm{n}=6$. (C) Representative of FVEP tracings of the four groups. (D, E) The data of FVEP indicated a higher amplitude and a shorter latency in AAV2-Pim-1 group compared with AAV2-GFP group. Compared with AAV2-GFP group, ${ }^{* * *} \mathrm{p}<0.001 ; \mathrm{n}=6$.

olfactory cortex, striatum and retina, implying that Pim-1 may participate in the development of neural and retinal structures [20]. During embryonic developmental stages of zebrafish, GCL expresses Pim-1, which is accompanied with the retinal development and formation of zebrafish [30].

In the present study, we successfully constructed AAV2-Pim-1 and found that it exhibited strong infection specificity in RGCs of the rat retina, and that Pim-1 mRNA and protein expressions in the retina were obviously up-regulated. Afterwards, the survival of RGCs was increased, the number of apoptotic GCL cells was decreased, the number of regenerated axons was increased, and recovery of visual function was promoted after optic nerve injury.

To sum up, the Pim-1 overexpression in the retina in vivo promoted survival of RGCs and revived the regenerative ability of 
A

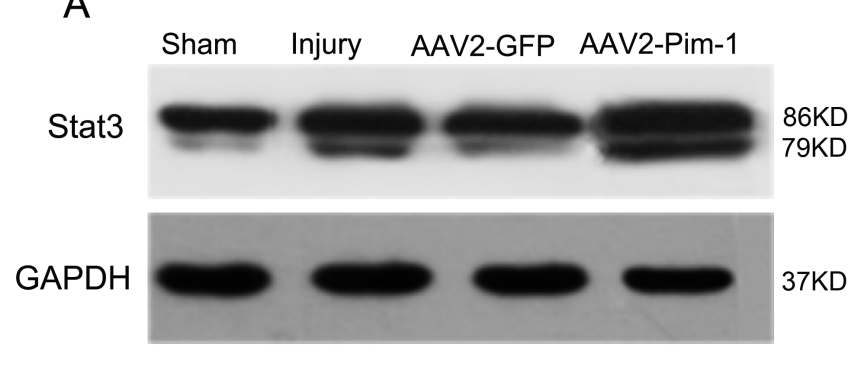

C
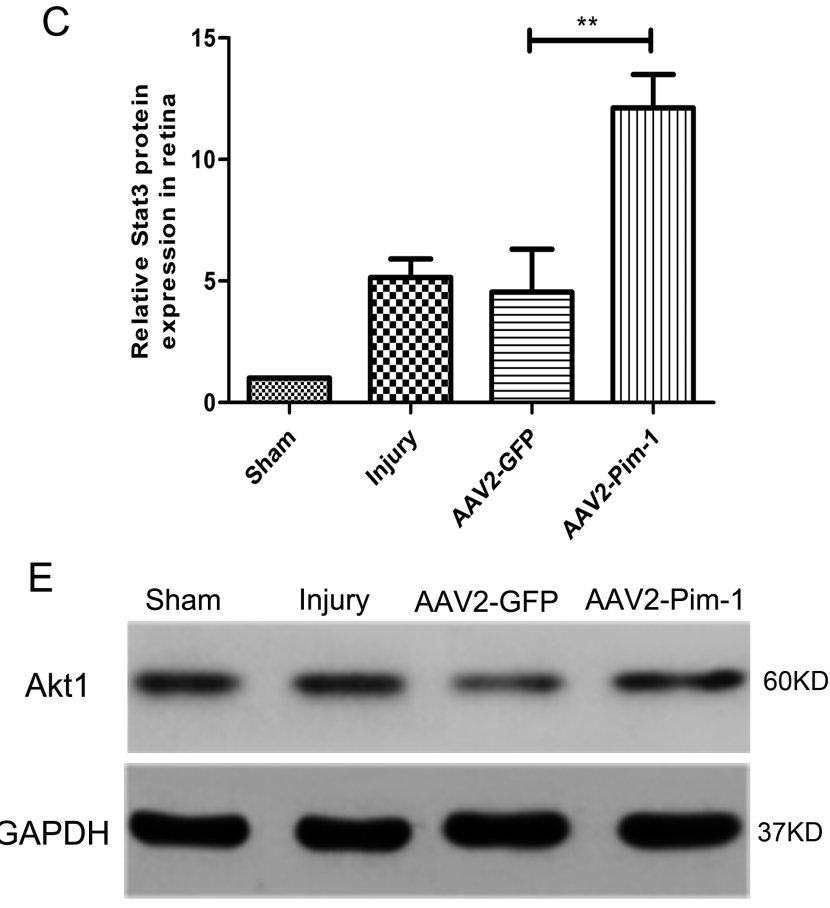

G

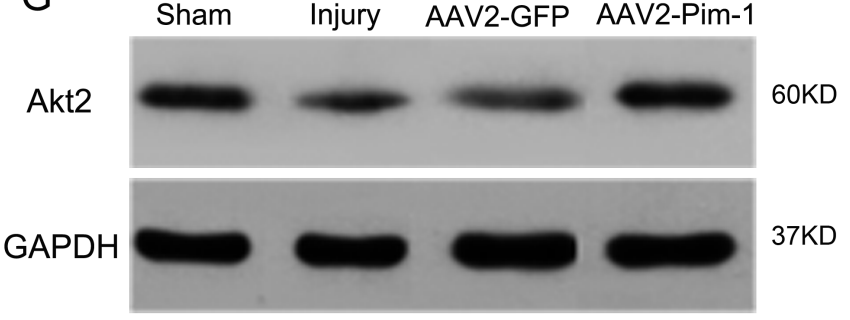

B

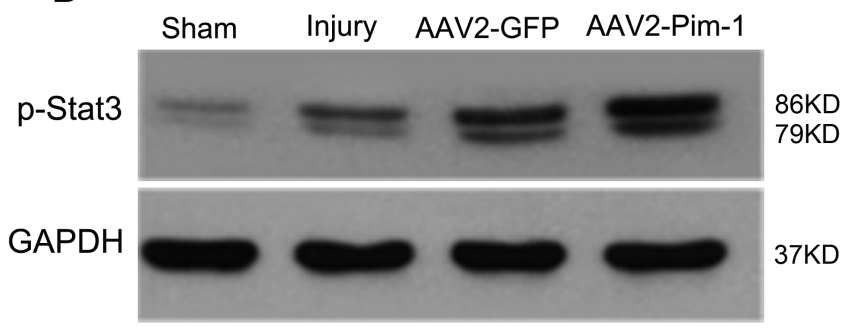

D

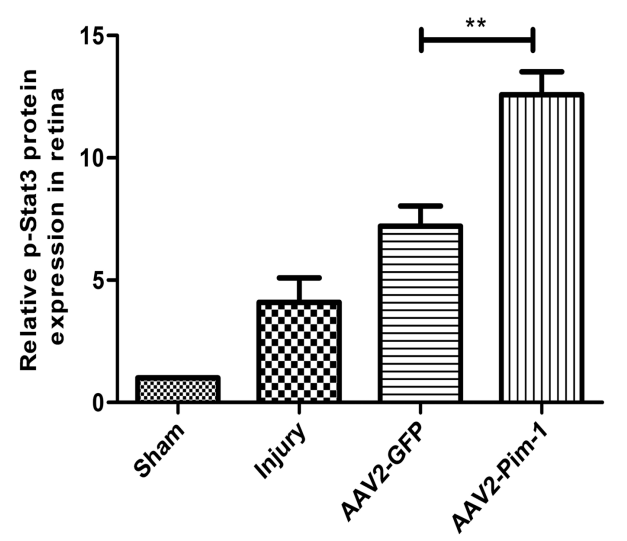

$\mathrm{F}$

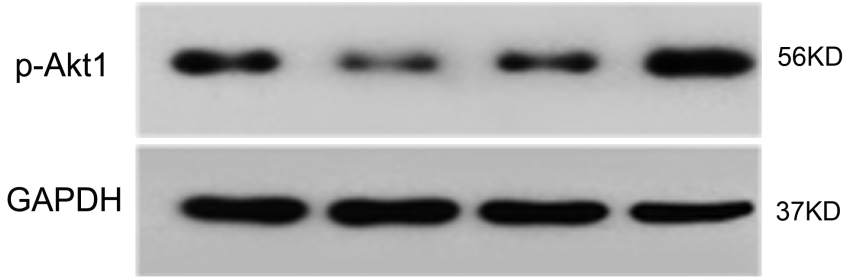

$\mathrm{H}$ Sham Injury AAV2-GFP AAV2-Pim-1

p-Akt2

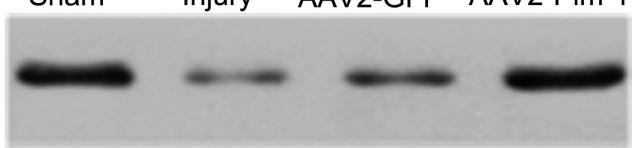

60KD

GAPDH

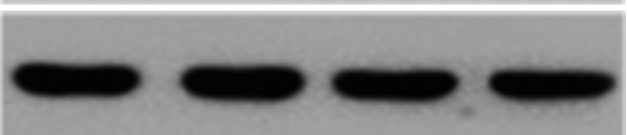

$37 K D$

Fig. 7. Protein expressions of the key retinal signaling pathways in the ONC model in vivo. Animals were intravitreally injected with either AAV2-GFP or AAV2-Pim-1. Two weeks later, animals were subjected to ONC and retinas were harvested 2 weeks post injury. (A, B, E, F, G, H, M, N, O, P) Western blot analysis of the retinal lysates from AAV2-GFP and AAV2-Pim-1 animals using antibodies against Stat3, p-Stat3, Akt1, p-Akt1, Akt2, p-Akt2, Erk1/2, p-Erk1/2, SOCS1 and SOCS3. GAPDH served as loading control. Western blotting was used to detect the retinal protein expression. (C, D, I, J, K, L, Q, R, S, T) Quantification by densitometry of retinal lysates between the four groups for mentioned-above molecules, normalized to GAPDH loading control. Compared with AAV2-GFP group, ${ }^{*} \mathrm{p}<0.05,{ }^{* *} \mathrm{p}<0.01,{ }^{* * *} \mathrm{p}<0.001,{ }^{*} \mathrm{p}>0.05 ; \mathrm{n}=6$.

the injured axons. Finally, the preserved neurons promoted the recovery of visual function after $\mathrm{ON}$ injury, and then we further demonstrated the mechanism underlying the role of Pim-1 at the molecular level.
The related molecules underlying the role of Pim-1 in enhancing the intrinsic regeneration ability of injured RGCs

Apoptosis-related molecules

The expression of Caspase 3 is increased after acute neuronal 
I

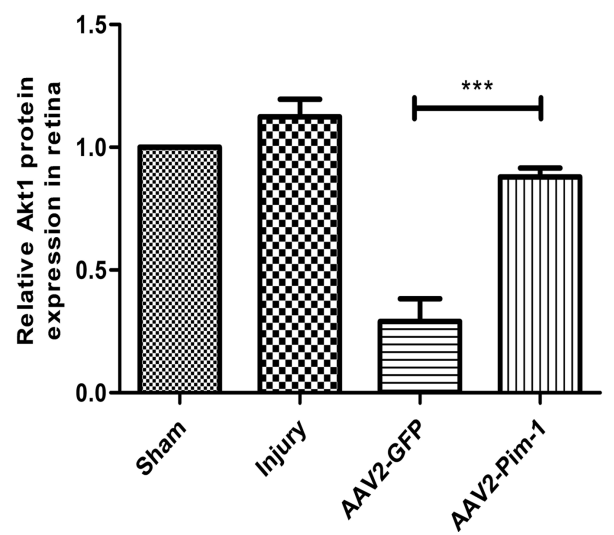

K

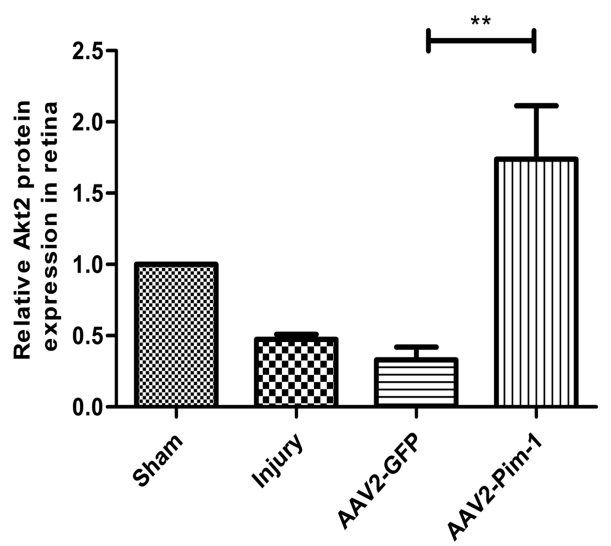

M

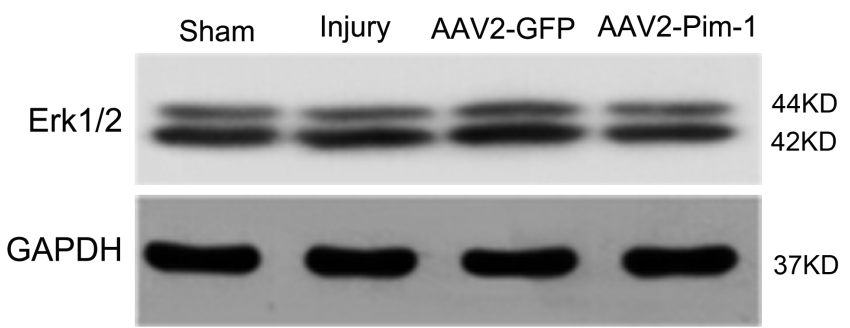

$\mathrm{O}$

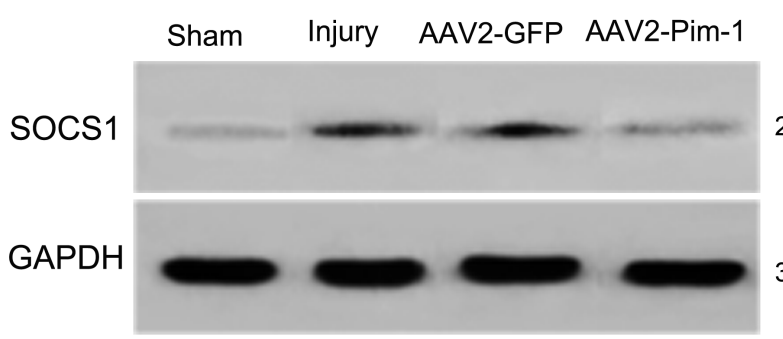

$J$

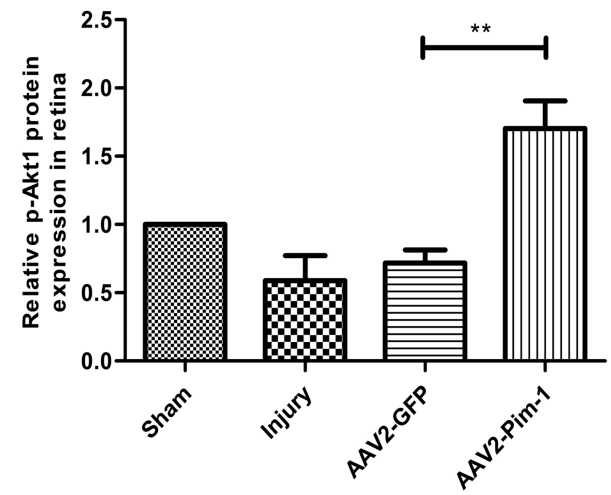

$\mathrm{L}$

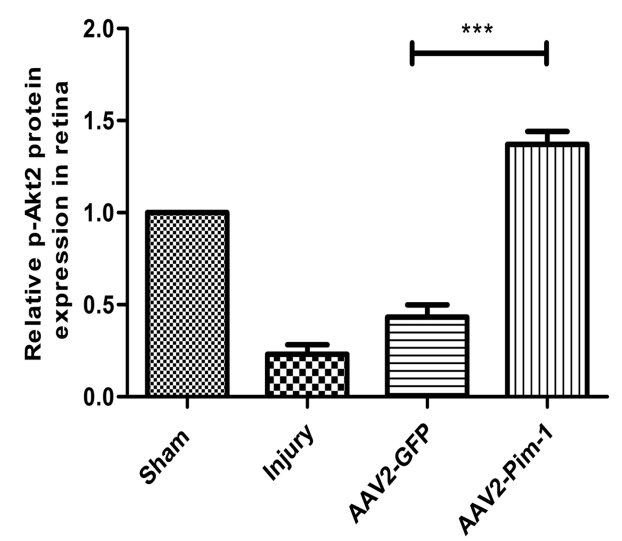

$\mathrm{N}$

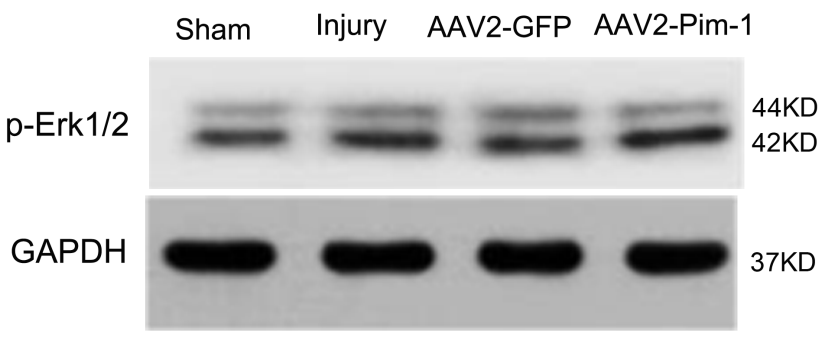

$\mathrm{P}$

socs3

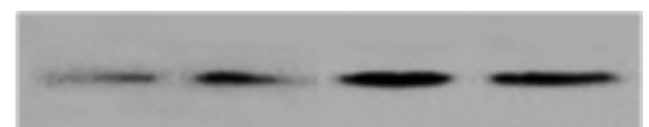

24.7KD

GAPDH
Sham Injury AAV2-GFP AAV2-Pim-1

$37 \mathrm{KD}$

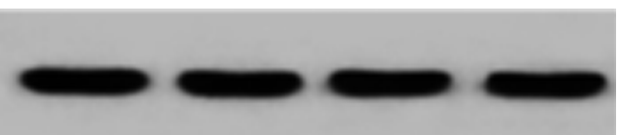

Fig. 7. Continued.

injury, and increased slightly in glial cells [42]. After optic nerve injury, down-regulation of Caspase 3 and Bax expression could promote the survival of damaged RGCs [43]. P21 activated kinase 5 could prevent localization of Bad on mitochondria, thus inhibit- ing cell apoptosis induced by camptothecin and ceramide [44].

The up-regulation of Pim-1 expression contributes to the proliferative and antiapoptotic pathways induced by FLT3 signaling in leukemia cells [45]. After hypoxia pretreatment, the expression of 


\section{Q}

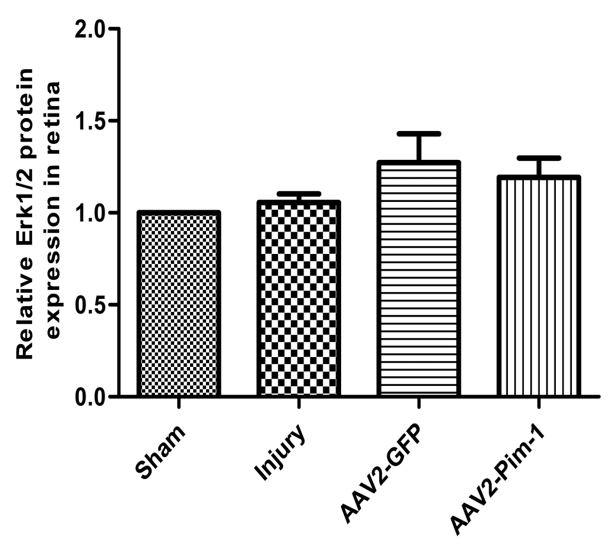

S

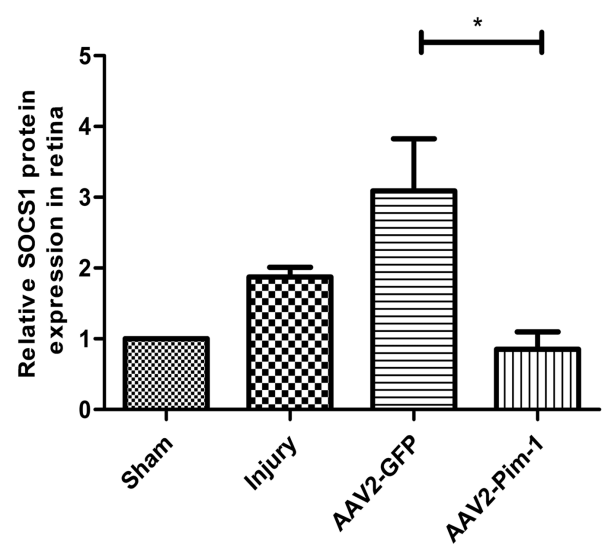

R

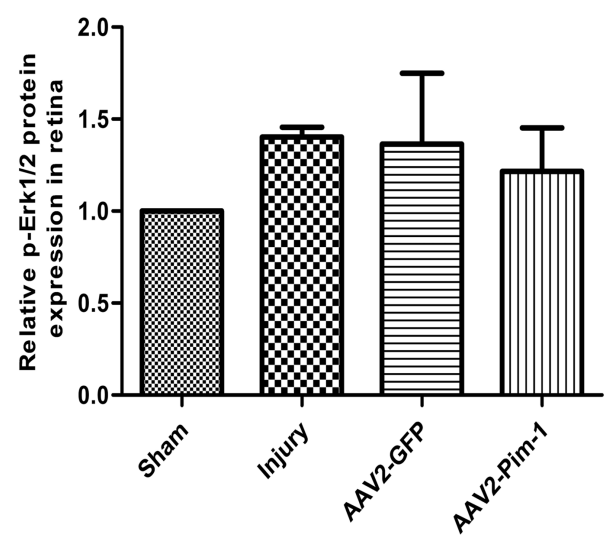

T

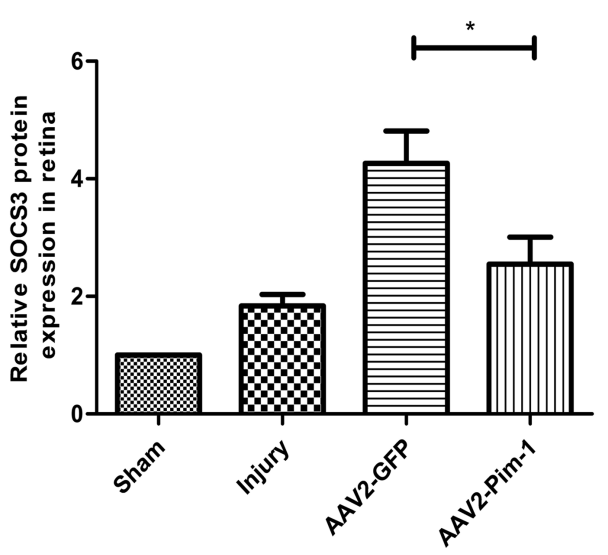

Fig. 7. Continued.

Table 3. Quantitative expression of molecules of cell survival- and growth-related pathways in the rat retina

\begin{tabular}{lcccc} 
Molecules & Sham & Injury & AAV2-GFP & AAV2-Pim-1 \\
\hline Stat3 & 1.00 & $5.14 \pm 1.33$ & $4.54 \pm 3.06$ & $12.11 \pm 2.38^{* *}$ \\
p-Stat3 & 1.00 & $4.10 \pm 1.72$ & $7.21 \pm 1.44$ & $12.58 \pm 1.62^{* *}$ \\
Akt1 & 1.00 & $1.12 \pm 0.13$ & $0.29 \pm 0.16$ & $0.88 \pm 0.06^{* * *}$ \\
p-Akt1 & 1.00 & $0.59 \pm 0.32$ & $0.72 \pm 0.17$ & $1.70 \pm 0.35^{* *}$ \\
Akt2 & 1.00 & $0.47 \pm 0.06$ & $0.33 \pm 0.16$ & $1.74 \pm 0.65^{* *}$ \\
p-Akt2 & 1.00 & $0.23 \pm 0.09$ & $0.43 \pm 0.12$ & $1.37 \pm 0.12^{* * *}$ \\
Erk1/2 & 1.00 & $1.06 \pm 0.10$ & $1.27 \pm 0.32$ & $1.19 \pm 0.21^{*}$ \\
p-Erk1/2 & 1.00 & $1.40 \pm 0.09$ & $1.36 \pm 0.67$ & $1.22 \pm 0.41^{*}$ \\
SOCS1 & 1.00 & $1.87 \pm 0.24$ & $3.09 \pm 1.28$ & $0.85 \pm 0.43^{*}$ \\
SOCS3 & 1.00 & $1.84 \pm 0.34$ & $4.26 \pm 0.96$ & $2.55 \pm 0.80^{*}$ \\
\hline
\end{tabular}

Compared with AAV2-GFP group, ${ }^{*} \mathrm{p}<0.05,{ }^{* *} \mathrm{p}<0.01,{ }^{* * *} \mathrm{p}<0.001,{ }^{*} \mathrm{p}>0.05$.

Pim-1 was up-regulated, apoptotic proteins such as cytochrome $\mathrm{C}$ and activated Caspase 3 were down-regulated, and the expression of $\mathrm{p}$-Bad related to cell survival was upregulated, so as to reduce mitochondrial damage and promote the survival of human cardiac progenitor cells [22]. In HCT-116 colon carcinoma cells, Caspase 3 and Bax showed a statistically significant increased activity upon Pim-1 knockdown, demonstrating an antiapoptotic role of Pim-1 through Caspase 3 and Bax [46]. After myocardial infarction in mice, Pim-1 could phosphorylate serine 112 in Bad, mediate desfluran-induced myocardial ischemic post-adaptation and increasing myocardial cell survival [47].

It was found in this study that the expression of Cleaved caspase 3, Bax and Bad in the retina was down-regulated after Pim-1 overexpression. These data indicate that Pim-1 overexpression could promote the survival of RGCs and reduce the apoptosis of RGCs after optic nerve injury, which may be achieved by down-regulating the expression of Cleaved caspase 3, Bax and Bad.

\section{Axonal regeneration-related molecules}

Moody et al. [48] showed that low $\beta$ III-tubulin expression was found in the early stage of differentiation in newborn rats. With the growth of the cells, the expression of $\beta$ III-tubulin was highly expressed at day 4 of differentiation, and the expression of $\beta I I I-$ tubulin decreased at day 7 of differentiation, suggesting that $\beta I I I-$ tubulin may participate in and promote neuronal differentiation 
A
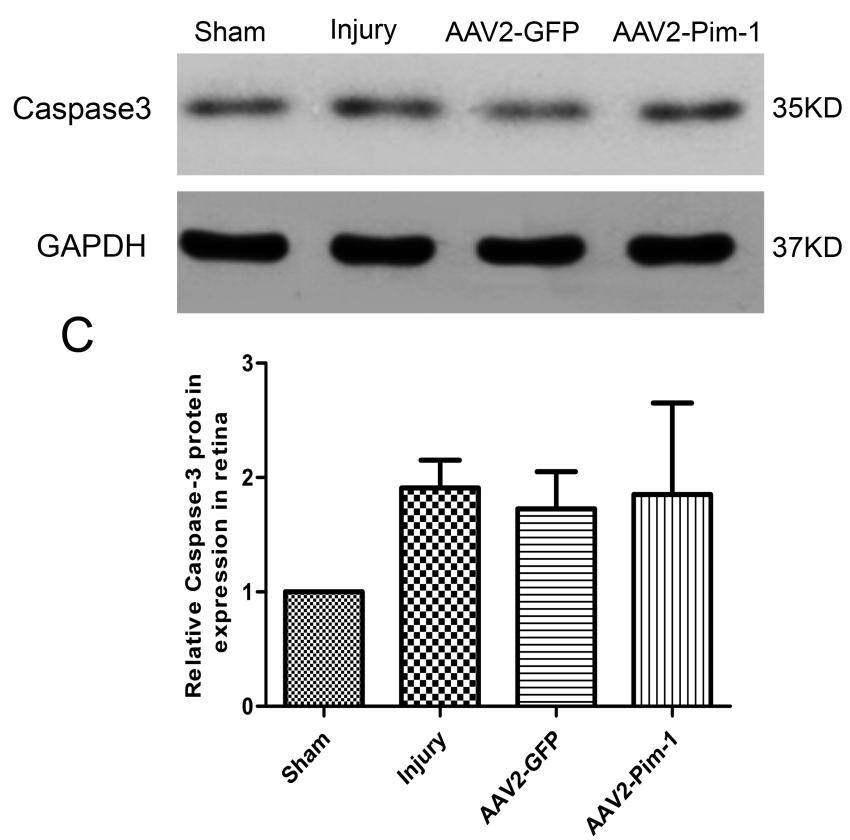

E
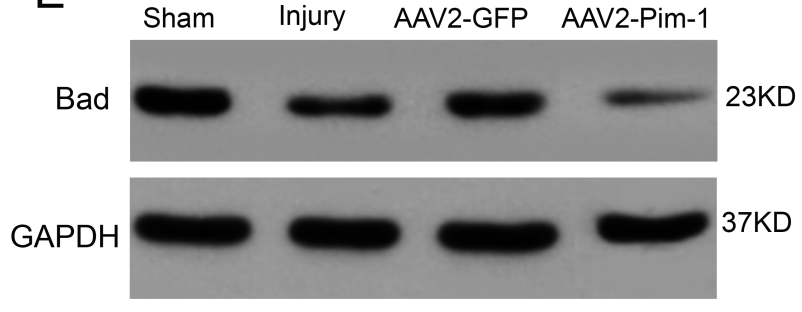

G

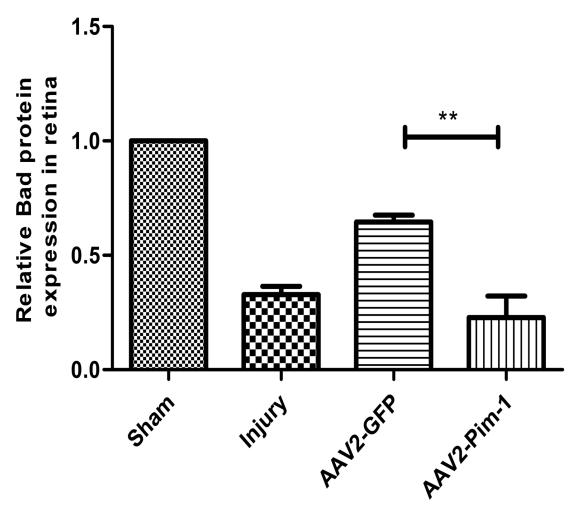

B

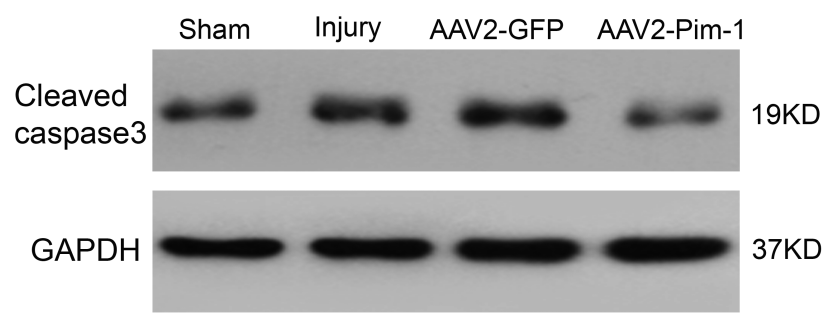

D

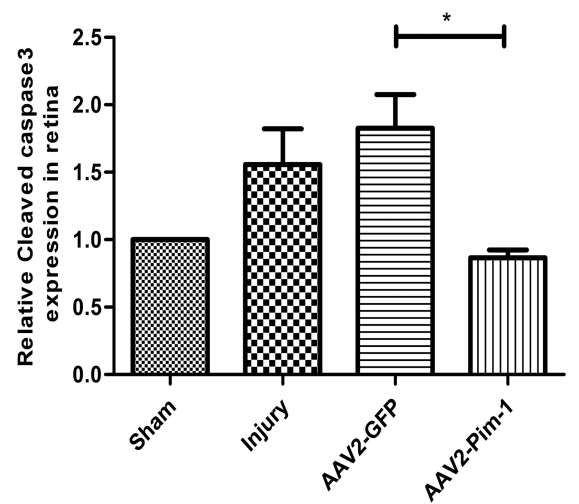

$\mathrm{F}$

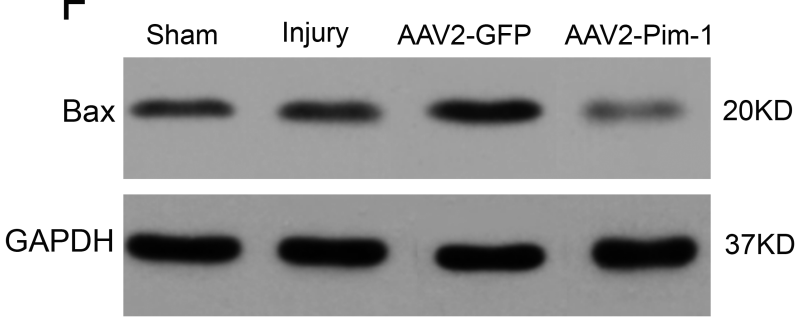

$\mathrm{H}$

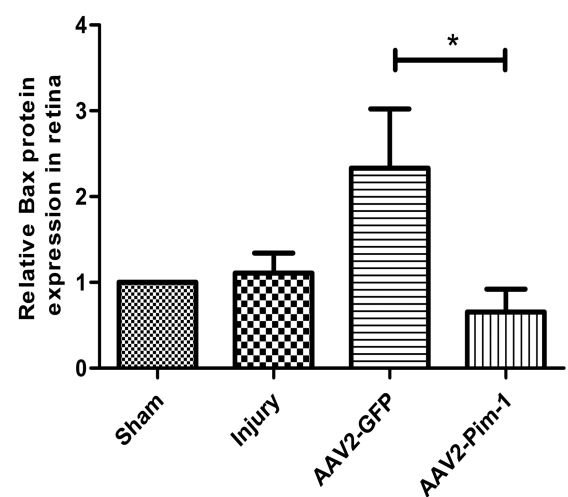

Fig. 8. Pim-1 suppressed the expression of Cleaved caspase 3, Bad and Bax apoptosis-related protein. (A, B, E, F) Western blot analysis of retinal lysates from the animals of the four groups using antibodies against Caspase 3, Cleaved caspase 3, Bad and Bax. (C, D, G, H) The band intensities for the mentioned-above molecules were quantified, normalized to GAPDH loading control. Compared with AAV2-GFP group, ${ }^{*} \mathrm{p}<0.05,{ }^{* *} \mathrm{p}<0.01,{ }^{*} \mathrm{p}>0.05 ; \mathrm{n}=6$.

[48]. In the rat model of ONC, GAP-43 was elevated slightly in the early week of ONC. After a period of two weeks, the expression began declining. The failure of axonal regeneration may be attributed to the weak expression of GAP-43 in RGCs, suggesting that GAP43 expression in RGCs is required in the treatment of optic nerve injury [49]. In GAP-43 knockout mice, RGC axons in the optic chiasma disappeared and the lack of GAP-43 expression inhibited the regeneration of axons in vitro [50].

Myocardial regeneration and repair were significantly enhanced by genetic engineering of cardiac progenitor cells with Pim-1 ki- 
nase. Ex vivo gene delivery to enhance cellular survival, proliferation, and regeneration may overcome current limitations of stem cell-based therapeutic approaches [51]. Research revealed that $\beta$ III-tubulin behaved as a gateway for Pim-1 to move into the cytoskeleton resulting in dynamic instability of microtubules in the ovarian cancer cells. Both $\beta$ III-tubulin and GAP-43 were distributed in axons and their growth cones in the developing and adult regenerating axons $[52,53]$.

It was found in this study that the expression of $\beta$ III-tubulin and GAP-43 protein in the retina was downregulated markedly after optic nerve injury, and significantly upregulated after the overexpression of Pim-1, suggesting that Pim-1 overexpression promoted axonal regeneration of the damaged optic nerve, probably by upregulating expression of $\beta$ III-tubulin and GAP-43 protein and together incorporating into in microtubules in the retina.

Table 4. Quantitative expression of cell apoptosis- and survival-related proteins in the rat retina

\begin{tabular}{lcccc}
\hline \multicolumn{1}{c}{ Molecules } & Sham & Injury & AAV2-GFP & AAV2-Pim-1 \\
\hline Caspase 3 & 1.00 & $1.91 \pm 0.47$ & $1.73 \pm 0.65$ & $1.85 \pm 1.60$ \\
Cleaved caspase 3 & 1.00 & $1.56 \pm 0.46$ & $1.83 \pm 0.43$ & $0.87 \pm 0.10^{*}$ \\
Bad & 1.00 & $0.33 \pm 0.06$ & $0.65 \pm 0.05$ & $0.23 \pm 0.16^{* *}$ \\
Bax & 1.00 & $1.11 \pm 0.47$ & $2.33 \pm 1.39$ & $0.66 \pm 0.53^{*}$ \\
\hline
\end{tabular}

Compared with AAV2-GFP group, ${ }^{*} \mathrm{p}<0.05,{ }^{* *} \mathrm{p}<0.01$.

\section{Signaling pathway-related molecules}

Recent studies have shown that the intrinsic regeneration of the damaged RGCs could be enhanced by targeting the gene expression of some molecules, such as knocking down the expression of PTEN in the Akt pathway and SOCS3 in the Jak-Stat pathways, and activating the expression of B-Raf in the Raf-Mek pathway. As a result, the regenerated axons could reach the superior colliculus and lateral geniculate bodies to promote the recovery of visual function [54]. Stat3 participates in cell proliferation, differentiation, survival and apoptosis, and promotes survival of RGCs after optic nerve injury $[55,56]$. Overexpression of Stat 3 in vivo promoted regeneration of injured axons, and survival of RGC5 was decreased by inhibiting the expression of Stat3 [57].

Studies show that Akt1 and Akt3 are mainly located in GCL, inner nuclear layer and outer nuclear layer, and Akt 2 is rarely expressed in the retina $[58,59]$. As Pim-1 kinases had overlapping many activity with Akt, and Akt and Pim-1 kinases shared substrates in common, it had been suggested that Pim-1 could play an important role in the activation of Akt [60], and Akt activation could induce Pim-1 expression [61]. The expression of Pim-1 was controlled on the transcriptional level through the Jak/Stat pathway involving Stat3 and/or Stat5 [62-64]. Meanwhile, upon siRNA-mediated Pim-1 knockdown, a down-regulation of Stat 3 with phosphorylation at Tyr705 was detected [46]. Pim-1 interacted

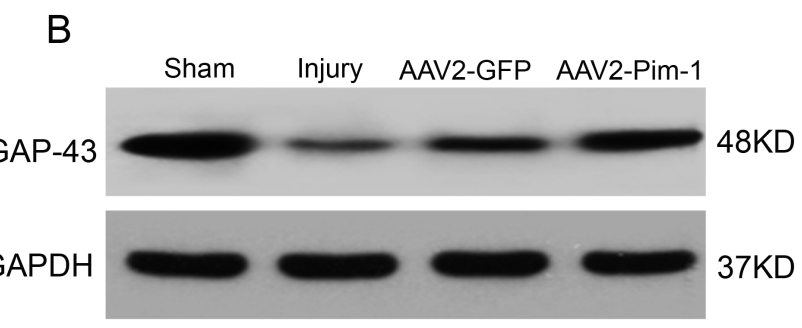

C

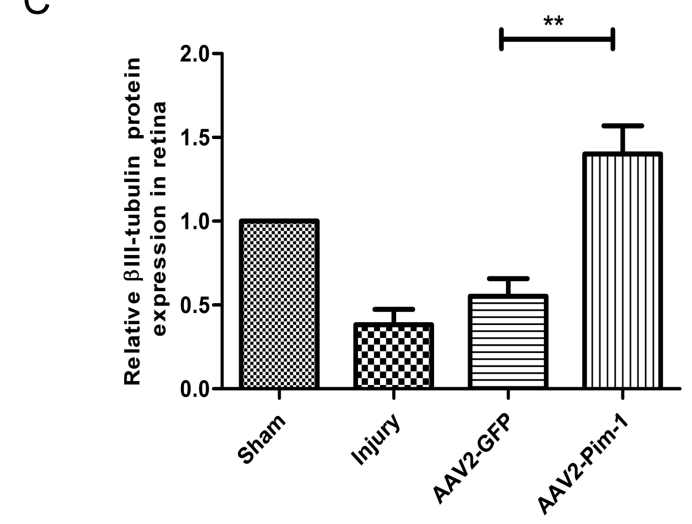

$55 K D$ $37 K D$
A

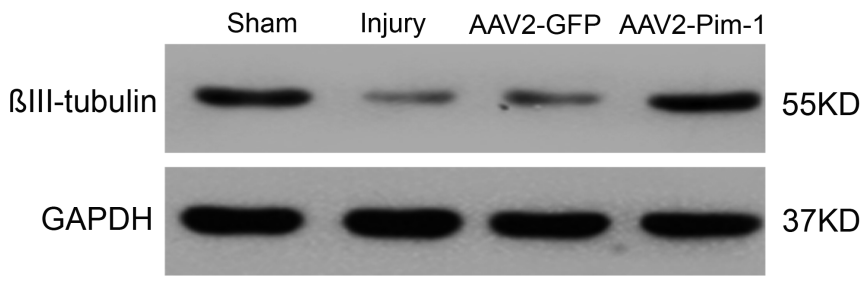

D

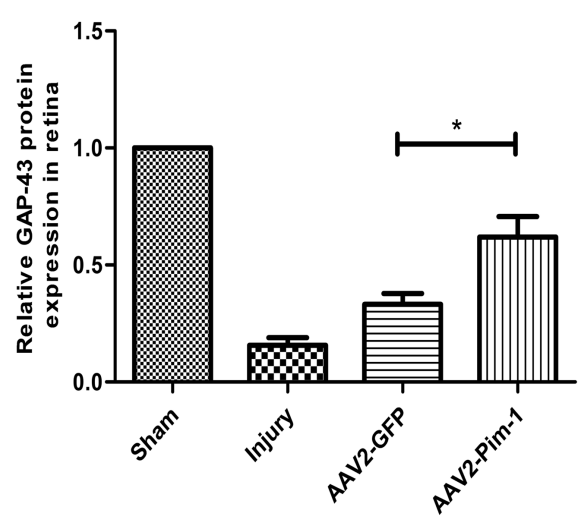

Fig. 9. Pim-1 boosted the expression of $\beta$ III-tubulin and GAP-43 axonal regeneration-related protein. (A, B) Western blot analysis of retinal lysates using antibodies against $\beta$ III-tubulin and GAP-43. (C, D) Quantification of $\beta$ III-tubulin and GAP-43 protein band intensities in the retinas treated with AAV2-Pim-1. The results were normalized to the GAPDH loading control. Compared with AAV2-GFP group, ${ }^{*} \mathrm{p}<0.05,{ }^{* *} \mathrm{p}<0.01 ; \mathrm{n}=6$. 

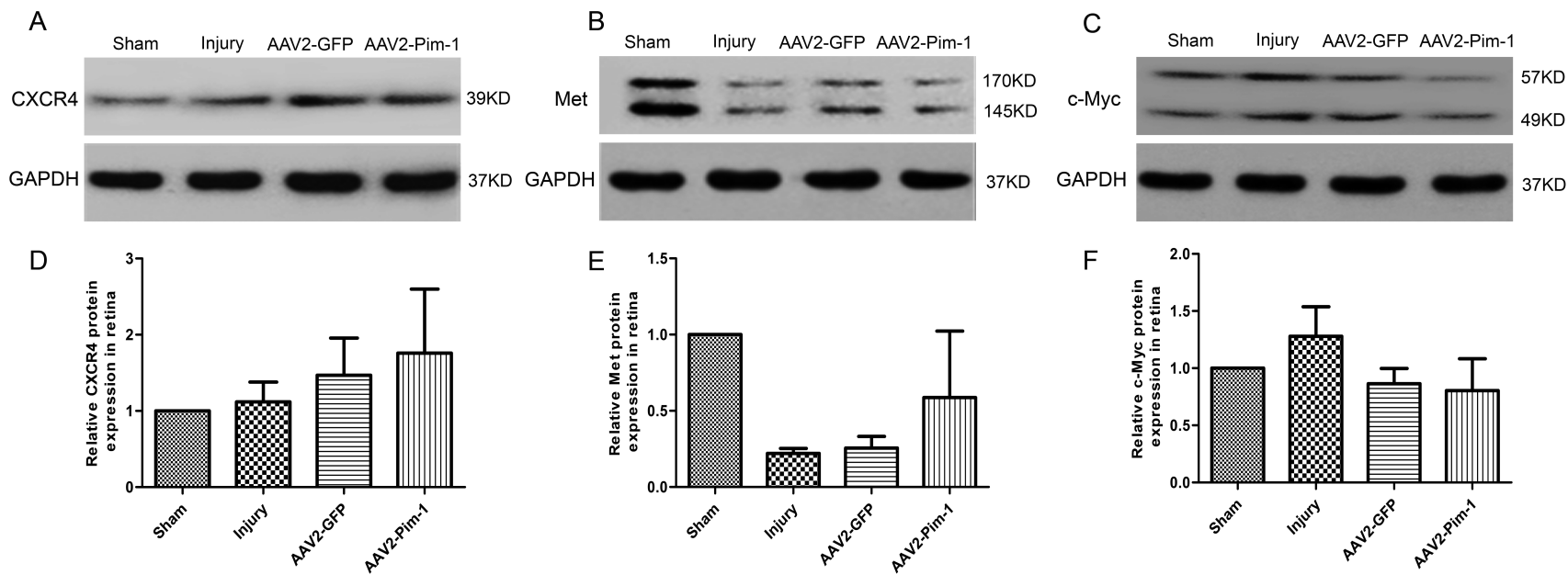

Fig. 10. Expression of tumor invasion-related proteins in the rat retinas of four groups. (A C) Expression of CXCR4, Met and c-Myc protein in the four groups was detected by Western blotting. (D F) The quantitative results showed that the expression of CXCR4, Met and c-Myc proteins in the retinas of AAV2-Pim-1 group was not significantly different from that in AAV2-GFP group. ${ }^{*} \mathrm{p}>0.05 ; \mathrm{n}=6$.

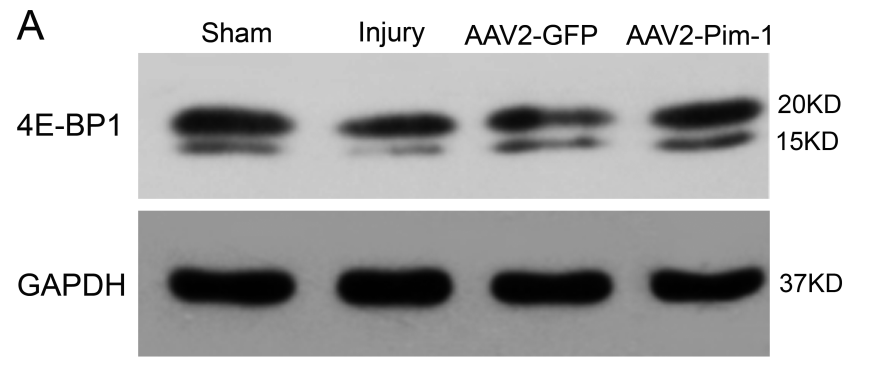

B

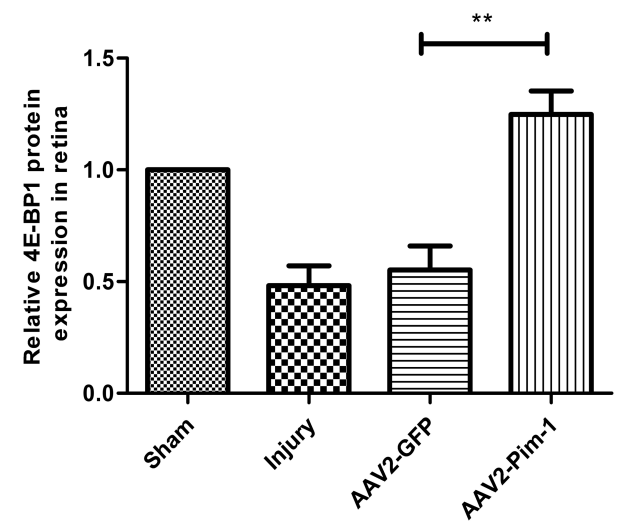

Fig. 11. Pim-1 promotes the expression of 4E-BP1. (A) Detection of the $4 \mathrm{E}-\mathrm{BP} 1$ protein content in the four groups by Western blotting. (B) Quantitative results of $4 \mathrm{E}-\mathrm{BP} 1$ expression in the retina of the four groups. The expression of 4E-BP1 protein in AAV2-Pim-1 group was significantly higher than that in AAV2-GFP group. Compared with the AAV2-GFP group, ${ }^{* *} \mathrm{p}<0.01 ; \mathrm{n}=6$. with SOCS1 and SOCS3 and potentiated their inhibitory effects on Stat 3 and/or Stat5, most likely via phosphorylation-mediated stabilization of the SOCS proteins [65]. At the same time, lentiviral delivery of short hairpin RNA to decrease SOCS3 expression into NS- 1 cells enhanced IL-6-induced tyrosine phosphorylation of Stat3 and promoted neurite outgrowth [66]. In summary, Pim-1 directly regulated Akt1, Akt2 and Stat3, and simultaneously acted on SOCS1 and SOCS3, then affected Stat3 expression through SOCS1 and SOCS3.

Akt inhibition was validated by observing the down-regulated levels of p-Aktl as well as the altered levels of the downstream targets of p-Akt, namely upregulated levels of pro-apoptotic markers, Bad, Bax and Caspase-9/3 $[67,68]$. Akt2 known as a signal pathway against ischemia and hypoxia, which played an neuroprotective role by inhibiting cell apoptosis and autophagy through regulating the expression of Caspase 3 and Bax [69]. Knockdown of KLF11 elevated the expression of p-JAK2 and p-Stat3 in H9c2, then suppressed the expression of Cleaved caspase3, promoted cell survival [70]. Stat3 phosphorylation enhanced Stat3 nuclear translocation, increased the Bcl-2/Bax ratio, and decreased Cleaved caspase 3 [71]. In short, Pim-1 interacted with Akt1, Akt2 and Stat3, and the Akt1, Akt2 and Stat 3 acted on the downstream molecules of Cleaved caspase 3, Bax and Bad, affecting cell apoptosis and cell survival.

The phosphorylation of JNK subsequently induced activation of Stat 1 and Stat 3 that led to expressions of $\beta$ III-tubulin and GAP43 , and ultimately promoted the differentiation of ES cell neurons [72]. MiR-17-5p inhibitor promoted the expression of Stat3 and 
p-Stat3, and then boosted the expression of GAP-43, finally promoted axon growth of the cortical neuron [73]. Akt2, EF1 $\alpha$ and potentially $\beta$-tubulin may form part of a signaling complex targeted to sites of cell activity via association with the cytoskeleton and as such may be important in the regulation of cell motility and growth [74]. In brief, Akt1, Akt 2 and Stat 3 acted on $\beta$ III-tubulin and GAP-43, affecting cytoskeleton and promoting axonal growth.

In this experiment, we detected the protein expression of cell survival and growth signaling pathways, such as Stat3, p-Stat3, Akt1, p-Akt1, Akt2, p-Akt2, Erk1/2, p-Erk1/2, SOCS1 and SOCS3. After optic nerve injury, Pim-1 overexpression up-regulated the expression of Stat3, p-Stat3, Akt1, p-Akt1, Akt2 and p-Akt2, and downregulated the expression of SOCS1 and SOCS3 in the retina. But it had little effect on the expression of Erk1/2 and p-Erk1/2 protein. The results suggest that Pim-1 overexpression could activate its Stat3, Akt1 and Akt2 pathways, then inhibit cell apoptosis and promote survival of RGCs by down-regulating the expression of Cleaved caspase 3, Bax and Bad, enhance regeneration of injured axons by upregulating expression of $\beta$ III-tubulin and GAP-43, and ultimately enhance the intrinsic regeneration of RGCs and recovery of visual function.

\section{E-BP1}

4E-BP1 participates in protein translation of eukaryotic cells and overexpresses in tumor cells. In aggressive B cell lymphoma, increasing the ratio of eIF4E to $4 \mathrm{E}-\mathrm{BP}$ through overexpression or knockout of eIF4E or 4E-BP1/2 could protect lymphoma cells [75]. SGI-1776 is a small molecule and Pim kinase inhibitor with selectivity for Pim-1. Pim-1 kinase function can be inhibited by SGI-1776 in mantle cell lymphoma and that inhibition of phosphorylation of downstream substrates such as 4E-BP1, ultimately will disrupt transcriptional, translational, and cell cycle processes and promote cell death [76].

It was found in our experiment that the expression of 4E-BP1 protein in the retina was obviously reduced after optic nerve injury, and up-regulated following the overexpression of Pim-1 in the retina, suggesting that Pim-1 overexpression could regulate the expression of proteins in the retina after ONC, probably by upregulating the expression of $4 \mathrm{E}-\mathrm{BP} 1$ protein in the retina and then affecting the protein translation.

\section{Tumor invasion and metastasis-related molecules}

The latest research shows that CXCR4 can be used as a new vascular marker in the bud of liver cancer in vitro and in vivo, which may provide a potential therapeutic target for the treatment of liver cancer patients [77]. C-Myc is overexpressed in many malignant tumors, including gastric cancer. In mouse gastric cancer models, bile acid promoted tumor progression and telomerase activity, mainly depending on the expression of c-Myc [78]. Met can participate in the transduction of cell signaling and remodeling of the cytoskeleton, regulate the process of cell proliferation and differentiation, and is closely related to tumor cell invasion and tumor neovascularization [79].

CXCR4, c-Myc and Met are oncogenes in the downstream of Pim- 1 has been reported in human tumors, mainly in hematologic malignancies recently. In vitro and in vivo studies have confirmed oncogenic potential of Pim-1 through phosphorylating the downstream substrates of CXCR4, c-Myc and Met [19]. To observe whether Pim-1 overexpression could induce up-regulation of tumor invasion-related molecules, we detected the expression of CXCR4, c-Myc, and Met in the rat retina and found that the expression of CXCR4, Met and c-Myc protein in the retina was not significantly affected by Pim-1 overexpression, suggesting that Pim-1 overexpression in the retina had little effect on tumorigenicity in the rat retina.

In conclusion, our research demonstrated a distinct neuroprotective and regeneration-promoting strategy to prevent RGC degeneration after ONC. Pim-1 overexpression in the retina could activate its Stat 3 , Akt1 and Akt 2 pathways, then inhibit cell apoptosis and promote survival of RGCs via the mitochondrial pathway, and enhance regeneration of injured axons by upregulating $\beta$ IIItubulin and GAP-43, and ultimately enhance the intrinsic regeneration of RGCs and recovery of visual function. These findings may provide an experimental basis for the clinical treatment of optic nerve damage by targeting the expression of Pim-1.

\section{ACKNOWLEDGEMENTS}

This study was supported by the grant of the National Natural Science Foundation of China (No. 31571239, 31271282).

\section{CONFLICT OF INTEREST}

All authors declare that they have no conflict of interests.

\section{AUTHOR CONTRIBUTIONS}

Jiajun Xu designed and analyzed data, conceived and designed the experiments and offered technical advice. Shoumei Zhang performed most of the experiments and wrote the original drafts of the paper. Li Shuai, Dong Wang, Tingting Huang, Shengsheng Yang, Mingyong Miao and Fang Liu reviewed and edited the original drafts of the paper, performed some experiments. Jiajun $\mathrm{Xu}$ directed the study and approved the final drafts. 


\section{REFERENCES}

1. Magharious M, D'Onofrio PM, Hollander A, Zhu P, Chen J, Koeberle PD (2011) Quantitative iTRAQ analysis of retinal ganglion cell degeneration after optic nerve crush. J Proteome Res 10:3344-3362.

2. Schwartz M (2004) Optic nerve crush: protection and regeneration. Brain Res Bull 62:467-471.

3. Fischer D, Pavlidis M, Thanos S (2000) Cataractogenic lens injury prevents traumatic ganglion cell death and promotes axonal regeneration both in vivo and in culture. Invest Ophthalmol Vis Sci 41:3943-3954.

4. Joachim SC, Mondon C, Gramlich OW, Grus FH, Dick HB (2014) Apoptotic retinal ganglion cell death in an autoimmune glaucoma model is accompanied by antibody depositions. J Mol Neurosci 52:216-224.

5. O'Donovan KJ, Ma K, Guo H, Wang C, Sun F, Han SB, Kim H, Wong JK, Charron J, Zou H, Son YJ, He Z, Zhong J (2014) BRAF kinase drives developmental axon growth and promotes axon regeneration in the injured mature CNS. J Exp Med 211:801-814.

6. Sun F, Park KK, Belin S, Wang D, Lu T, Chen G, Zhang K, Yeung C, Feng G, Yankner BA, He Z (2011) Sustained axon regeneration induced by co-deletion of PTEN and SOCS3. Nature 480:372-375.

7. Benowitz LI, Yin Y (2007) Combinatorial treatments for promoting axon regeneration in the CNS: strategies for overcoming inhibitory signals and activating neurons' intrinsic growth state. Dev Neurobiol 67:1148-1165.

8. Quigley HA, McKinnon SJ, Zack DJ, Pease ME, KerriganBaumrind LA, Kerrigan DF, Mitchell RS (2000) Retrograde axonal transport of BDNF in retinal ganglion cells is blocked by acute IOP elevation in rats. Invest Ophthalmol Vis Sci 41:3460-3466.

9. Huang Y, Xu Y, Cheng Q, Yu S, Gao Y, Shu Q, Yang C, Sun Y, Wang J, Xu F, Liang X (2014) The expression changes of myelin and lymphocyte protein (MAL) following optic nerve crush in adult rats retinal ganglion cells. J Mol Neurosci 54:614-621.

10. Silver J, Miller JH (2004) Regeneration beyond the glial scar. Nat Rev Neurosci 5:146-156.

11. Benowitz L, Yin Y (2008) Rewiring the injured CNS: lessons from the optic nerve. Exp Neurol 209:389-398.

12. Kikuchi M, Tenneti L, Lipton SA (2000) Role of p38 mitogenactivated protein kinase in axotomy-induced apoptosis of rat retinal ganglion cells. J Neurosci 20:5037-5044.

13. Leaver SG, Cui Q, Bernard O, Harvey AR (2006) Cooperative effects of bcl-2 and AAV-mediated expression of CNTF on retinal ganglion cell survival and axonal regeneration in adult transgenic mice. Eur J Neurosci 24:3323-3332.

14. Yungher BJ, Luo X, Salgueiro Y, Blackmore MG, Park KK (2015) Viral vector-based improvement of optic nerve regeneration: characterization of individual axons' growth patterns and synaptogenesis in a visual target. Gene Ther 22:811-821.

15. Leaver SG, Cui Q, Plant GW, Arulpragasam A, Hisheh S, Verhaagen J, Harvey AR (2006) AAV-mediated expression of CNTF promotes long-term survival and regeneration of adult rat retinal ganglion cells. Gene Ther 13:1328-1341.

16. Nawabi H, Belin S, Cartoni R, Williams PR, Wang C, Latremolière A, Wang X, Zhu J, Taub DG, Fu X, Yu B, Gu X, Woolf CJ, Liu JS, Gabel CV, Steen JA, He Z (2015) Doublecortin-like kinases promote neuronal survival and induce growth cone reformation via distinct mechanisms. Neuron 88:704-719.

17. Sharma TP, Liu Y, Wordinger RJ, Pang IH, Clark AF (2015) Neuritin 1 promotes retinal ganglion cell survival and axonal regeneration following optic nerve crush. Cell Death Dis 6:e1661.

18. Fox CJ, Hammerman PS, Thompson CB (2005) The Pim kinases control rapamycin-resistant $\mathrm{T}$ cell survival and activation. J Exp Med 201:259-266.

19. Mondello P, Cuzzocrea S, Mian M (2014) Pim kinases in hematological malignancies: where are we now and where are we going? J Hematol Oncol 7:95.

20. Eichmann A, Yuan L, Bréant C, Alitalo K, Koskinen PJ (2000) Developmental expression of pim kinases suggests functions also outside of the hematopoietic system. Oncogene 19:12151224.

21. Hofmann AD, Takahashi T, Duess J, Gosemann JH, Puri P (2015) Increased expression of activated PSTAT3 and PIM1 in the pulmonary vasculature of experimental congenital diaphragmatic hernia. J Pediatr Surg 50:908-911.

22. Hu S, Yan G, Xu H, He W, Liu Z, Ma G (2014) Hypoxic preconditioning increases survival of cardiac progenitor cells via the pim-1 kinase-mediated anti-apoptotic effect. Circ J 78:724-731.

23. Samse K, Emathinger J, Hariharan N, Quijada P, Ilves K, Völkers M, Ormachea L, De La Torre A, Orogo AM, Alvarez R, Din S, Mohsin S, Monsanto M, Fischer KM, Dembitsky WP, Gustafsson ÅB, Sussman MA (2015) Functional effect of Pim1 depends upon intracellular localization in human cardiac progenitor cells. J Biol Chem 290:13935-13947.

24. Liu W, Feldman JD, Machado HB, Vician LJ, Herschman HR (2003) Expression of depolarization-induced immediate early gene proteins in PC12 cells. J Neurosci Res 72:670-678. 
25. Zhang Y, Brownstein AJ, Buonora M, Niikura K, Ho A, Correa da Rosa J, Kreek MJ, Ott J (2015) Self administration of oxycodone alters synaptic plasticity gene expression in the hippocampus differentially in male adolescent and adult mice. Neuroscience 285:34-46.

26. Yata K, Matchett GA, Tsubokawa T, Tang J, Kanamaru K, Zhang JH (2007) Granulocyte-colony stimulating factor inhibits apoptotic neuron loss after neonatal hypoxia-ischemia in rats. Brain Res 1145:227-238.

27. de Vries M, Heijink IH, Gras R, den Boef LE, Reinders-Luinge M, Pouwels SD, Hylkema MN, van der Toorn M, Brouwer U, van Oosterhout AJ, Nawijn MC (2014) Piml kinase protects airway epithelial cells from cigarette smoke-induced damage and airway inflammation. Am J Physiol Lung Cell Mol Physiol 307:L240-L251.

28. Xu Z, Gwin KA, Li Y, Medina KL (2016) Developmental stage-specific effects of Pim-1 dysregulation on murine bone marrow B cell development. BMC Immunol 17:16.

29. Zhang Y, Lei W, Yan W, Li X, Wang X, Zhao Z, Hui J, Shen Z, Yang J (2016) microRNA-206 is involved in survival of hypoxia preconditioned mesenchymal stem cells through targeting Pim-1 kinase. Stem Cell Res Ther 7:61.

30. Yin J, Shine L, Raycroft F, Deeti S, Reynolds A, Ackerman KM, Glaviano A, O'Farrell S, O'Leary O, Kilty C, Kennedy C, McLoughlin S, Rice M, Russell E, Higgins DG, Hyde DR, Kennedy BN (2012) Inhibition of the Piml oncogene results in diminished visual function. PLoS One 7:e52177.

31. Berry M, Carlile J, Hunter A (1996) Peripheral nerve explants grafted into the vitreous body of the eye promote the regeneration of retinal ganglion cell axons severed in the optic nerve. J Neurocytol 25:147-170.

32. Huang L, Hu F, Xie X, Harder J, Fernandes K, Zeng XY, Libby R, Gan L (2014) Pou4f1 and pou4f2 are dispensable for the long-term survival of adult retinal ganglion cells in mice. PLoS One 9:e94173.

33. Liu Y, McDowell CM, Zhang Z, Tebow HE, Wordinger RJ, Clark AF (2014) Monitoring retinal morphologic and functional changes in mice following optic nerve crush. Invest Ophthalmol Vis Sci 55:3766-3774.

34. Sun JC, Xu T, Zuo Q, Wang RB, Qi AQ, Cao WL, Sun AJ, Sun XJ, Xu J (2014) Hydrogen-rich saline promotes survival of retinal ganglion cells in a rat model of optic nerve crush. PLoS One 9:e99299.

35. Livak KJ, Schmittgen TD (2001) Analysis of relative gene expression data using real-time quantitative PCR and the 2(-Delta Delta C(T)) Method. Methods 25:402-408.

36. Grozdanic S, Betts DM, Allbaugh RA, Sakaguchi DS, Kwon
YH, Kardon RH, Sonea IM (2003) Characterization of the pupil light reflex, electroretinogram and tonometric parameters in healthy mouse eyes. Curr Eye Res 26:371-378.

37. Chan KM, Young MJ, Lund RD (1995) Interactive events subserving the pupillary light reflex in pigmented and albino rats. Eur J Neurosci 7:2053-2063.

38. So KF, Yip HK (1998) Regenerative capacity of retinal ganglion cells in mammals. Vision Res 38:1525-1535.

39. Yang P, Yang Z (2012) Enhancing intrinsic growth capacity promotes adult CNS regeneration. J Neurol Sci 312:1-6.

40. Feldman JD, Vician L, Crispino M, Tocco G, Marcheselli VL, Bazan NG, Baudry M, Herschman HR (1998) KID-1, a protein kinase induced by depolarization in brain. J Biol Chem 273:16535-16543.

41. Zhang Y, Parsanejad M, Huang E, Qu D, Aleyasin H, Rousseaux MW, Gonzalez YR, Cregan SP, Slack RS, Park DS (2010) Pim-1 kinase as activator of the cell cycle pathway in neuronal death induced by DNA damage. J Neurochem 112:497510.

42. Beer R, Franz G, Srinivasan A, Hayes RL, Pike BR, Newcomb JK, Zhao X, Schmutzhard E, Poewe W, Kampfl A (2000) Temporal profile and cell subtype distribution of activated caspase-3 following experimental traumatic brain injury. J Neurochem 75:1264-1273.

43. Krueger A, Baumann S, Krammer PH, Kirchhoff S (2001) FLICE-inhibitory proteins: regulators of death receptormediated apoptosis. Mol Cell Biol 21:8247-8254.

44. Cotteret S, Jaffer ZM, Beeser A, Chernoff J (2003) p21-Activated kinase 5 (Pak5) localizes to mitochondria and inhibits apoptosis by phosphorylating BAD. Mol Cell Biol 23:55265539.

45. Kim KT, Baird K, Ahn JY, Meltzer P, Lilly M, Levis M, Small D (2005) Pim-1 is up-regulated by constitutively activated FLT3 and plays a role in FLT3-mediated cell survival. Blood 105:1759-1767.

46. Weirauch U, Beckmann N, Thomas M, Grünweller A, Huber K, Bracher F, Hartmann RK, Aigner A (2013) Functional role and therapeutic potential of the pim-1 kinase in colon carcinoma. Neoplasia 15:783-794.

47. Stumpner J, Smul TM, Redel A, Hilz T, Tischer-Zeitz T, Eisenbarth H, Schick MA, Kehl F, Roewer N, Lange M (2012) Desflurane-induced and ischaemic postconditioning against myocardial infarction are mediated by Pim-1 kinase. Acta Anaesthesiol Scand 56:904-913.

48. Moody SA, Miller V, Spanos A, Frankfurter A (1996) Developmental expression of a neuron-specific beta-tubulin in frog (Xenopus laevis): a marker for growing axons during the 
embryonic period. J Comp Neurol 364:219-230.

49. Zhang C, Guo Y, Slater BJ, Miller NR, Bernstein SL (2010) Axonal degeneration, regeneration and ganglion cell death in a rodent model of anterior ischemic optic neuropathy (rAION). Exp Eye Res 91:286-292.

50. Zhu Q, Julien JP (1999) A key role for GAP-43 in the retinotectal topographic organization. Exp Neurol 155:228-242.

51. Fischer KM, Cottage CT, Wu W, Din S, Gude NA, Avitabile D, Quijada P, Collins BL, Fransioli J, Sussman MA (2009) Enhancement of myocardial regeneration through genetic engineering of cardiac progenitor cells expressing Pim-1 kinase. Circulation 120:2077-2087.

52. Andreoli M, Persico M, Kumar A, Orteca N, Kumar V, Pepe A, Mahalingam S, Alegria AE, Petrella L, Sevciunaite L, Camperchioli A, Mariani M, Di Dato A, Novellino E, Scambia G, Malhotra SV, Ferlini C, Fattorusso C (2014) Identification of the first inhibitor of the GBP1:PIM1 interaction. Implications for the development of a new class of anticancer agents against paclitaxel resistant cancer cells. J Med Chem 57:7916-7932.

53. De Donato M, Mariani M, Petrella L, Martinelli E, Zannoni GF, Vellone V, Ferrandina G, Shahabi S, Scambia G, Ferlini C (2012) Class III $\beta$-tubulin and the cytoskeletal gateway for drug resistance in ovarian cancer. J Cell Physiol 227:10341041.

54. Stankowska DL, Minton AZ, Rutledge MA, Mueller BH 2nd, Phatak NR, He S, Ma HY, Forster MJ, Yorio T, Krishnamoorthy RR (2015) Neuroprotective effects of transcription factor Brn3b in an ocular hypertension rat model of glaucoma. Invest Ophthalmol Vis Sci 56:893-907.

55. Ip NY, McClain J, Barrezueta NX, Aldrich TH, Pan L, Li Y, Wiegand SJ, Friedman B, Davis S, Yancopoulos GD (1993) The alpha component of the CNTF receptor is required for signaling and defines potential CNTF targets in the adult and during development. Neuron 10:89-102.

56. Zhang W, Zong CS, Hermanto U, Lopez-Bergami P, Ronai Z, Wang LH (2006) RACK1 recruits STAT3 specifically to insulin and insulin-like growth factor 1 receptors for activation, which is important for regulating anchorage-independent growth. Mol Cell Biol 26:413-424.

57. Pernet V, Joly S, Dalkara D, Jordi N, Schwarz O, Christ F, Schaffer DV, Flannery JG, Schwab ME (2013) Long-distance axonal regeneration induced by CNTF gene transfer is impaired by axonal misguidance in the injured adult optic nerve. Neurobiol Dis 51:202-213.

58. Reiter CE, Gardner TW (2003) Functions of insulin and insulin receptor signaling in retina: possible implications for diabetic retinopathy. Prog Retin Eye Res 22:545-562.
59. Reiter CE, Sandirasegarane L, Wolpert EB, Klinger M, Simpson IA, Barber AJ, Antonetti DA, Kester M, Gardner TW (2003) Characterization of insulin signaling in rat retina in vivo and ex vivo. Am J Physiol Endocrinol Metab 285:E763E774.

60. Cen B, Mahajan S, Wang W, Kraft AS (2013) Elevation of receptor tyrosine kinases by small molecule AKT inhibitors in prostate cancer is mediated by Pim-1. Cancer Res 73:34023411 .

61. Muraski JA, Rota M, Misao Y, Fransioli J, Cottage C, Gude N, Esposito G, Delucchi F, Arcarese M, Alvarez R, Siddiqi S, Emmanuel GN, Wu W, Fischer K, Martindale JJ, Glembotski CC, Leri A, Kajstura J, Magnuson N, Berns A, Beretta RM, Houser SR, Schaefer EM, Anversa P, Sussman MA (2007) Pim-1 regulates cardiomyocyte survival downstream of Akt. Nat Med 13:1467-1475.

62. Bachmann M, Möröy T (2005) The serine/threonine kinase Pim-1. Int J Biochem Cell Biol 37:726-730.

63. Heinrich PC, Behrmann I, Haan S, Hermanns HM, MüllerNewen G, Schaper F (2003) Principles of interleukin (IL)-6type cytokine signalling and its regulation. Biochem J 374(Pt 1):1-20.

64. Wang Z, Bhattacharya N, Weaver M, Petersen K, Meyer M, Gapter L, Magnuson NS (2001) Pim-1: a serine/threonine kinase with a role in cell survival, proliferation, differentiation and tumorigenesis. J Vet Sci 2:167-179.

65. Peltola KJ, Paukku K, Aho TL, Ruuska M, Silvennoinen O, Koskinen PJ (2004) Pim-1 kinase inhibits STAT5-dependent transcription via its interactions with SOCS1 and SOCS3. Blood 103:3744-3750.

66. Park KW, Lin CY, Li K, Lee YS (2015) Effects of reducing suppressors of cytokine signaling-3 (SOCS3) expression on dendritic outgrowth and demyelination after spinal cord injury. PLoS One 10:e138301.

67. Kashyap MP, Singh AK, Yadav DK, Siddiqui MA, Srivastava RK, Chaturvedi V, Rai N (2015) 4-Hydroxy-trans-2-nonenal (4-HNE) induces neuronal SH-SY5Y cell death via hampering ATP binding at kinase domain of Akt1. Arch Toxicol 89:243-258.

68. Wang S, Chong ZZ, Shang YC, Maiese K (2012) Wntl inducible signaling pathway protein 1 (WISP1) blocks neurodegeneration through phosphoinositide 3 kinase/Aktl and apoptotic mitochondrial signaling involving Bad, Bax, Bim, and Bcl-xL. Curr Neurovasc Res 9:20-31.

69. Miao W, Yan Y, Bao TH, Jia WJ, Yang F, Wang Y, Zhu YH, Yin M, Han JH (2020) Ischemic postconditioning exerts neuroprotective effect through negatively regulating PI3K/Akt2 
signaling pathway by microRNA-124. Biomed Pharmacother 126:109786

70. Li Y, Shi X, Li J, Zhang M, Yu B (2017) Knockdown of KLF11 attenuates hypoxia/reoxygenation injury via JAK2/STAT3 signaling in H9c2. Apoptosis 22:510-518.

71. Wang B, Guo H, Li X, Yue L, Liu H, Zhao L, Bai H, Liu X, Wu X, Qu Y (2018) Adiponectin attenuates oxygen-glucose deprivation-induced mitochondrial oxidative injury and apoptosis in hippocampal HT22 cells via the JAK2/STAT3 pathway. Cell Transplant 27:1731-1743.

72. Wei ZZ, Yu SP, Lee JH, Chen D, Taylor TM, Deveau TC, Yu AC, Wei L (2014) Regulatory role of the JNK-STAT1/3 signaling in neuronal differentiation of cultured mouse embryonic stem cells. Cell Mol Neurobiol 34:881-893.

73. Zhang L, Wang Z, Li B, Xia Z, Wang X, Xiu Y, Zhang Z, Chen C, Song H, Li W, Yu M, Zhang M, Wang K, Guo X, Ren L, Wang $\mathrm{T}$ (2020) The inhibition of miR-17-5p promotes cortical neuron neurite growth via STAT3/GAP-43 pathway Mol Biol Rep 47:1795-1802.

74. Lau J, Castelli LA, Lin EC, Macaulay SL (2006) Identification of elongation factor lalpha as a potential associated binding partner for Akt2. Mol Cell Biochem 286:17-22.

75. Bi C, Zhang X, Lu T, Zhang X, Wang X, Meng B, Zhang H, Wang P, Vose JM, Chan WC, McKeithan TW, Fu K (2017) Inhibition of 4EBP phosphorylation mediates the cytotoxic effect of mechanistic target of rapamycin kinase inhibitors in aggressive B-cell lymphomas. Haematologica 102:755-764.

76. Yang Q, Chen LS, Neelapu SS, Miranda RN, Medeiros LJ, Gandhi V (2012) Transcription and translation are primary targets of Pim kinase inhibitor SGI-1776 in mantle cell lymphoma. Blood 120:3491-3500.

77. Xu J, Liang J, Meng YM, Yan J, Yu XJ, Liu CQ, Xu L, Zhuang SM, Zheng L (2017) Vascular CXCR4 expression promotes vessel sprouting and sensitivity to sorafenib treatment in hepatocellular carcinoma. Clin Cancer Res 23:4482-4492.

78. Wang X, Sun L, Wang X, Kang H, Ma X, Wang M, Lin S, Liu M, Dai C, Dai Z (2017) Acidified bile acids enhance tumor progression and telomerase activity of gastric cancer in mice dependent on c-Myc expression. Cancer Med 6:788-797.

79. Migliore C, Giordano S (2008) Molecular cancer therapy: can our expectation be MET? Eur J Cancer 44:641-651. 